\title{
Pharmacological mechanism of immunomodulatory agents for the treatment of severe cases of COVID-19 infection
}

\author{
Zahra Bahari $^{1,2} \cdot$ Zohreh Jangravi $^{3} \cdot$ Hassan Ghoshooni ${ }^{1,2} \cdot$ Mohammad Reza Afarinesh $^{4} \cdot$ Gholam Hossein Meftahi $^{2} \oplus$
}

Received: 21 November 2020 / Revised: 2 February 2021 / Accepted: 10 February 2021 / Published online: 19 February 2021

(c) The Author(s), under exclusive licence to Springer Nature Switzerland AG part of Springer Nature 2021

\begin{abstract}
Objective Coronavirus disease 2019 (COVID-19) is a world-wide pandemic caused by severe acute respiratory syndrome coronavirus 2 (SARS-CoV-2). To date, treatment of severe COVID-19 is far from clear. Therefore, it is urgent to develop an effective option for the treatment of patients with COVID-19. Most patients with severe COVID-19 exhibit markedly increased serum levels of pro-inflammatory cytokines, including interferon (IFN)- $\alpha$, IFN- $\gamma$, and interleukin (IL)- $1 \beta$. Immunotherapeutic strategies have an important role in the suppression of cytokine storm and respiratory failure in patients with COVID-19.

Methods A systematic search in the literature was performed in PubMed, Scopus, Embase, Cochrane Library, Web of Science, as well as Google Scholar preprint database using all available MeSH terms for Coronavirus, SARS-CoV-2, antirheumatoid agents, COVID-19, cytokine storm, immunotherapeutic drugs, IFN, interleukin, JAK/STAT inhibitors, MCP, MIP, TNF.

Results Here, we first review common complications of COVID-19 patients, particularly neurological symptoms. We next explain host immune responses against COVID-19 particles. Finally, we summarize the existing experimental and clinical immunotherapeutic strategies, particularly anti-rheumatoid agents and also plasma (with a high level of gamma globulin) therapy for severe COVID-19 patients. We discuss both their therapeutic effects and side effects that should be taken into consideration for their clinical application.

Conclusion It is suggested that immunosuppressants, such as anti-rheumatoid drugs, could be considered as a potential approach for the treatment of cytokine storm in severe cases of COVID-19. One possible limitation of immunosuppressant therapy is their inhibitory effects on host anti-viral immune response. So, the appropriate timing of administration should be carefully considered.
\end{abstract}

Keywords Anti-rheumatoid agents · COVID-19 · Cytokine storm · Immunotherapeutic drugs

\section{Introduction}

Gholam Hossein Meftahi

hossein.meftahi@bmsu.ac.ir; meftahi208@yahoo.com

1 Department of Physiology and Medical Physics, Faculty of Medicine, Baqiyatallah University of Medical Sciences, Tehran, Iran

2 Neuroscience Research Center, Baqiyatallah University of Medical Sciences, Tehran, Iran

3 Department of Biochemistry, Faculty of Medicine, Baqiyatallah University of Medical Sciences, Tehran, Iran

4 Kerman Neuroscience Research Center, Institute of Neuropharmacology, Kerman University of Medical Sciences, Kerman, Iran
The three recent coronaviruses (CoVs) diseases, including Severe Acute Respiratory Syndrome CoV 1 (SARS-CoV-1), Middle East respiratory syndrome (MERS-CoV), and SARSCoV-2 (or COVID-19) is associated with the presence of the hyper-inflammatory condition. It is noteworthy COVID-19 pathogen in some elderly adults or adults with a health problem, leads to vigorous and uncontrollable activation of proinflammatory immune responses, so-called cytokine storm. Notably, elderly adults with COVID-19 had higher cytokine levels, including IL-2, IL-6, IL-7, IL-10, IP-10, and tumor necrosis factor $\alpha$ (TNF $\alpha)$ as compared to young or healthy adults $[1,2]$. It is reported that diffuse alveolar damage and alveolar edema are a common outcome of cytokine storm in 
severe cases of COVID-19 [3]. Additionally, excessive levels of pro-inflammatory cytokines may lead to higher blood viscosity and lethal thromboembolism in some elderly adults with COVID-19 [4]. Hyper-activation of pro-inflammatory markers in combination with a vascular injury can induce multiple organ dysfunction including the brain, heart, liver, and also kidney. Recently, it is reported that patients with COVID-19 suffer from various neurological symptoms ranging from anosmia to hemorrhagic encephalopathy and stroke risk. Additionally, Guillain-Barré syndrome is also observed in the COVID-19 patients [5]. For example, Toscano and colleagues in 2020 observed that five patients had Guillain-Barré syndrome following the onset of COVID-19. These patients suffer from limb weakness [6]. Recently, damage of the thalamus, brain stem, and cerebral white matter was observed in the cases with COVID-19 infection. Another neurological symptom of COVID-19 is impairment of the olfactory and gustatory function. This impairment in cases of COVID-19 is probably due to the infection of the epithelial cells of the nasal and oral mucosa [7]. There are high levels of angiotensin-converting enzyme 2 (ACE2) receptors (host receptors) in olfactory epithelial cells and oral mucosa. COVID-19 particles via binding to the ACE2 in the nasal cavity likely can suppress the function of sensory receptor cells that mediate olfaction and gustation [7]. Recently, Garcia and colleagues in 2021 evaluated neuroinflammatory alteration of the cerebrospinal fluid (CSF) of COVID-19 patients with neurological dysfunction and nonCOVID-19 cases with stroke. They reported that neurofilament light chain in CSF increased in patients with stroke and also severe cases of COVID-19. A high level of neurofilament light chain revealed the neuroaxonal injury in patients with COVID-19. However, they observed similar raise of inflammatory markers in CSF of COVID-19 and non-COVID-19 stroke cases as compared with the control group [8]. The pathophysiology of neurological symptoms in COVID-19 patients is far from clear. It seems that cytokine-induced pneumonia may adversely affect brain function because of the close correlation between the lungs and the respiratory centers in the brain stem. In addition to the indirect effects of cytokine storm, COVID-19 particles can enter the brain directly. The COVID-19 spike protein also can change the physiological function of the blood-brain barrier [9]. To understand how this pathologic process occurs, we need to know further details of the pathogenesis of cytokine storm in COVID-19. In the following, we are going to review host immune responses against COVID-19 particles.

\section{Host immune responses against COVID-19 particles}

The envelope-located trimeric spike protein (S protein) of COVID-19 particles attached to ACE2 receptors on the surface of host human cells. It is accepted that the structure of the S protein of COVID-19 particles and its affinity to the ACE2 receptor is highly similar to SARS-CoV-1 [2]. S protein of COVID-19 has 20-30 amino acids longer than SARS-CoV-1 [10]. Although, pathophysiological mechanism of COVID-19 is still sparse, however, the similarity between COVID-19 with SARS-CoV and MERS-CoV may allow us to understand possible mechanisms of COVID-19 [2]. Generally, as shown in Fig. 1, the viral RNAs, as pathogen-associated molecular patterns (PAMPs), detected by three sensors; (1) the pattern recognition receptors (PRRs), (2) cytoplasmic RNA sensors, and (3) cytoplasmic family of nucleotide-binding domain leucine-rich repeat (NLR) proteins. Among PRRs, the endosomal family of TollLike Receptors (TLRs), such as TLRs type 3 and 7 and 8 (TLR-3 and TLR7/8), are important for the detection of extracellular PAMPs, which are expressed by virus pathogens [4]. The cytoplasmic RNA sensors include retinoic acid-inducible gene I (RIG-I), melanoma differentiationassociated protein 5 (MDA5), and laboratory of genetics and physiology 2 (LGP2) [10]. The third set of viral pathogen sensors is a cytoplasmic family of NLR, including NLRP1, NLRP3, NLRP7, and NLRC4. These sensors have a critical role in the detection of intracellular dangerassociated molecular patterns (DAMPs) expressed inside the host cell [11, 12] (Fig. 1). Following virus recognition in several viral infections, activation of TLR3 and TLR7/8 and cytoplasmic RNA sensors leads to downstream transduction pathways, including activation of TNF receptorassociated factors 3 and 6 (TRAF3/6), nuclear factor $\mathrm{\kappa B}$ (NF- $\mathrm{KB}$ ), interferon regulatory factor 3 and 7 (IRF3/7), MAPK, JAK (Janus kinase)/STAT (signal transducer and activator of transcription). Then, activation of all of these downstream transduction pathways leads to the generation and release of several pro-inflammatory cytokines (e.g., IL-1 $\beta$, IL-6, TNF- $\alpha$ ), and type 1 IFNs $[10,13]$ (Fig. 1). Additionally, type I IFNs, a key cytokine in innate immunity, has anti-viral and anti-proliferative effects [13]. Also, it is reported that interaction of type I IFNs and its receptor (IFNAR) can activate the JAK1/ TYK2/STAT1, 2/IRF9 signal transduction pathway. These complexes translocate to the nucleus and activate the transcription of IFN-stimulated genes (ISG) [3]. These inflammatory, antiviral responses increased the clearance of viral pathogens (Fig. 1). However, in the case of coronavirus (CoVs) family (e.g., SARS-CoV, MERS-CoV, and COVID-19), they play a smart game for evasion of host anti-viral responses 


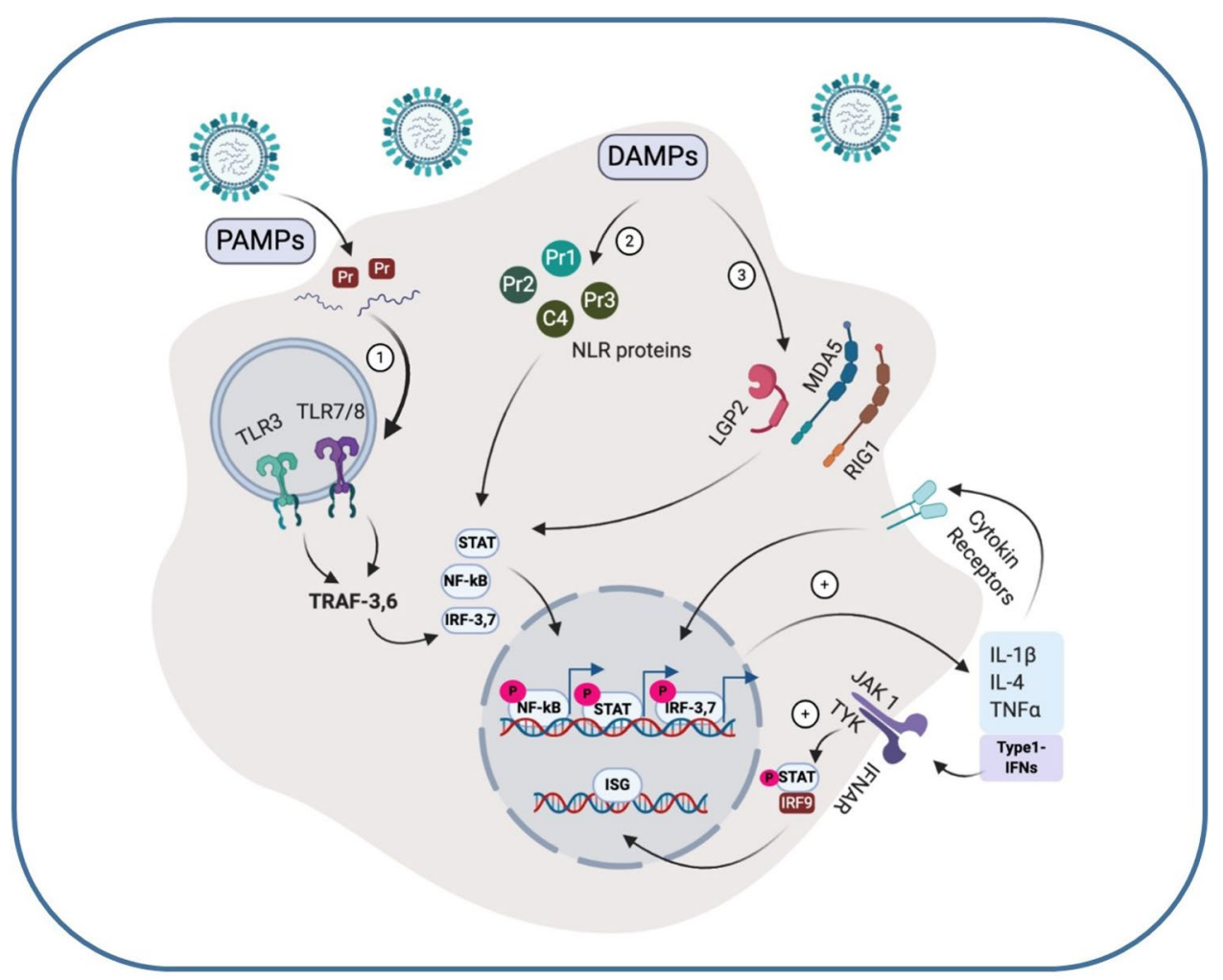

Fig. 1 Host immune responses against viral particles in a typical immune cell. The viral extracellular PAMPs and intracellular DAMPs detected by three sensors; (1) the endosomal TLRs, such as TLR-3 and TLR7/8, (2) the cytoplasmic NLR proteins, such as Pr1, Pr2, Pr3, and C4, (3) the cytoplasmic RNA sensors, such as RIG-I, MDA5, and LGP2. Activation of these sensors leads to downstream transduction pathways, including activation of TRAF3/6, NF-кB, IRF3/7, JAK/ STAT. Then, activation of all these transduction pathways leads to generation and release of several pro-inflammatory cytokines (e.g., IL-1 $\beta$, IL-6, TNF- $\alpha$, type 1 IFNs). Additionally, IL-1 $\beta$, IL-6, TNF- $\alpha$ and type I IFNs via their receptors (cytokine receptors and IFNAR) can increase their own generation via a positive feedback. These

in the early stage of infection [14] (Fig. 2). The CoVs family develops three important immune evasion strategies in the early stage of infection $[10,14]$. The first immune evasion strategy is the isolation of viral dsRNA (as extracellular PAMPs) in the double-membrane vesicles (DMVs). The DMVs can shield viral PAMPs from recognition by PRRs [14]. The second immune evasion strategy is the suppression of TRAF3/6, NF- $\mathrm{KB}$, and IRF3/7 in the host immune cells [13]. The third immune evasion strategy is inhibition of the function of IFN. It is reported that the anti-IFN proteins of CoVs (e.g., ORF3a protein and ORF6 protein) can decrease the IFNAR levels via degradation of its receptors (IFNAR) and also via disrupting of nuclear translocation of STAT [15] (Fig. 2). Therefore, suppression of immune mechanisms in the early stage of infection, allow COVID-19 particles to replicate without turning on the host anti-viral immune machine [10]. This immune inflammatory, anti-viral responses increased clearance of viral pathogens. $I L$ interleukin, $I F N$ interferones, IFNAR type I IFNs receptor, $I S G$ IFN-stimulated genes, PAMPs pathogen-associated molecular patterns, DAMPs danger-associated molecular patterns, TLRS TollLike Receptors, $N L R$ nucleotide-binding domain leucine-rich repeat, $R I G-I$ retinoic acid-inducible gene I, MDA5 melanoma differentiation-associated protein 5, LGP2 laboratory of genetics and physiology 2, TRAF TNF receptor-associated factors, $N F-\kappa B$ nuclear factor $\kappa \mathrm{B}, I R F$ interferon regulatory factor, JAK Janus kinase, STAT signal transducer and activator of transcription, $T Y K$ tyrosine kinase, $T N F \alpha$ tumor necrosis factor $\alpha$. Figure created using BioRender software

evasion could explain the longer incubation period of infection, which is about 2-11 days in COVID-19 [14]. However, at a late stage of infection (Fig. 3), COVID-19 particles, activate host immune anti-viral responses (TLRs, NLRs, and RIGI/MDA5/LGP2), leading to increased expression of pro-inflammatory cytokines. Notably, proinflammatory cytokines can increase their generation via an autocrine pathway. It is noteworthy COVID-19 particles only in some elderly adults or adults with a health problem, leads to un-controllable activation of inflammatory immune responses (cytokine storm) (Fig. 3). For example, elderly or weak adults with COVID-19 had higher cytokine levels, including, IL-2, IL-6, IL-7, IL-10, IP-10, and TNF $\alpha$ compared to those with mild infection $[1,2]$. It seems that the young adults have balanced between proinflammatory and anti-inflammatory cytokine networks. However, elderly patients do not have the same balanced 


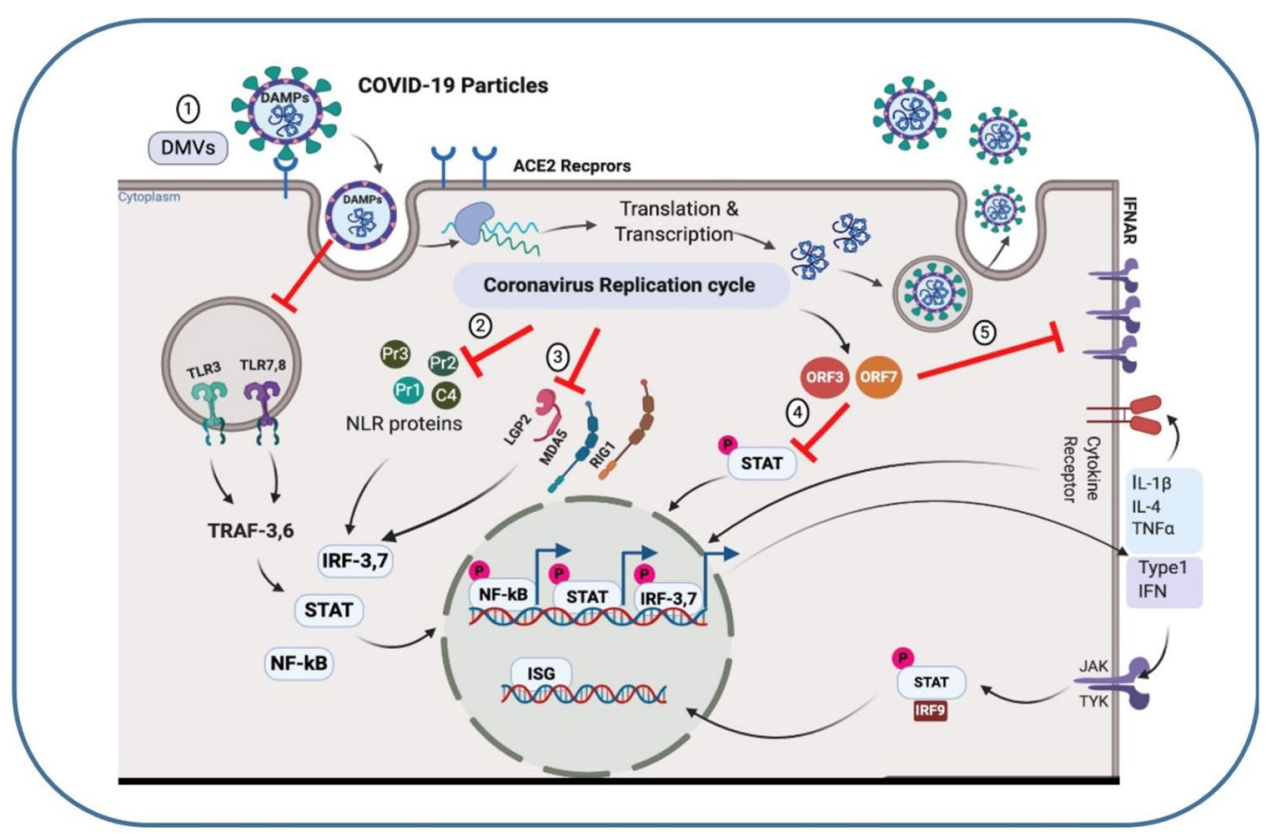

Fig. 2 Evasion mechanism of COVID-19 particles of host anti-viral responses in the early stage of infection. The COVID-19 particles similar to two previous CoV families (SARS-CoV1 and MERS-Cov) infection develops three important immune evasion strategies in the early stage of infection. The first immune evasion strategy is the isolation of viral PAMPs in the DMVs. The DMVs can shield viral PAMPs from recognition by TLRs. The second immune evasion strategy is suppression of TRAF3/6, NF- $\mathrm{kB}$, JAK/STAT and IRF3/7 in the host immune cells. The third immune evasion strategy is inhibition of IFN induction via the anti-IFN proteins such as ORF3a and ORF6 proteins. These anti-IFN proteins can suppress the IFNAR function via degradation of its receptors (IFNAR), and disrupting nuclear translocation of STAT. Therefore, suppression of host anti-

immune response. Several factors orchestrate the induction of cytokine storm in some elderly adults (Fig. 3) [16]. First, decreased antioxidant capacity during aging together with excess ROS generation, increasing pro-inflammatory cytokine secretion during aging and induce mild inflammatory conditions in aged subjects [17]. It is well accepted that excess ROS generation during aging can induce NLRs activation, leading to the generation of multiprotein cytoplasmic complexes, so-called inflammasomes. Then, the inflammasomes convert procaspase-1 (inactive form) to the active form of caspase- 1 . Subsequently, caspase- 1 converts pro-IL- $1 \beta$ to active IL- $1 \beta$ (Fig. 3). The excess release of IL-1 $\beta$ is associated with pyroptosis and cytokine storm in elderly adults with COVID-19 [11, 12]. Secondly, it is reported that ACE2 expression is significantly reduced with aging [18]. Interestingly, there is a negative association between ACE2 expression and COVID-19 fatality [19]. Despite the ACE2 is an entry-point receptor for viral mechanisms in the early stage of infection, allow COVID-19 particles to replicate without turning on the host anti-viral immune machine. ACE2 angiotensin converting enzyme, $D M V s$ double membrane vesicles, IL interleukin, IFN interferones, IFNAR type I IFNs receptor, ISG IFN-stimulated genes, TLRs Toll-Like Receptors, NLR nucleotide-binding domain leucine-rich repeat, $R I G-I$ retinoic acidinducible gene I, MDA5 melanoma differentiation-associated protein 5, LGP2 laboratory of genetics and physiology 2, TRAF TNF receptor-associated factors, $N F-\kappa B$ nuclear factor $\kappa \mathrm{B}, I R F$ interferon regulatory factor, $J A K$ Janus kinase, STAT signal transducer and activator of transcription, TYK tyrosine kinase, TNF $\alpha$ tumor necrosis factor $\alpha$, $O R F$ open reading frame. Figure created using BioRender software.

COVID-19 particles, however, high expression of ACE2 protected against severe lung injury both in children and an experimental mouse model (Fig. 3) [16]. Finally, the lack of vitamin $\mathrm{D}$ during aging likely is increasing the risk of cytokine storm in elderly adults (Fig. 3) [19]. Ebadi and Montano-Loza in 2020 reported that $70 \%$ mortality of COVID-19 was observed in patients with vitamin D deficiency in Chicago. They also revealed that vitamin $D$ has anti-inflammatory effects, suppressing the expression of pro-inflammatory markers, including IL- $1 \alpha$, IL- $1 \beta$, and TNF- $\alpha$. Hence, the lack of vitamin D in aged-subjects associated with cytokine storm in COVID-19 [20]. Taken together, COVID-19 particles can exaggeratedly increase the amplitude of the inflammatory immune machine and subsequently induce cytokine storm in some elderly or weak adults. Indeed, elderly and weak adults with severe COVID-19 infection cannot turn off their inflammatory machine. 


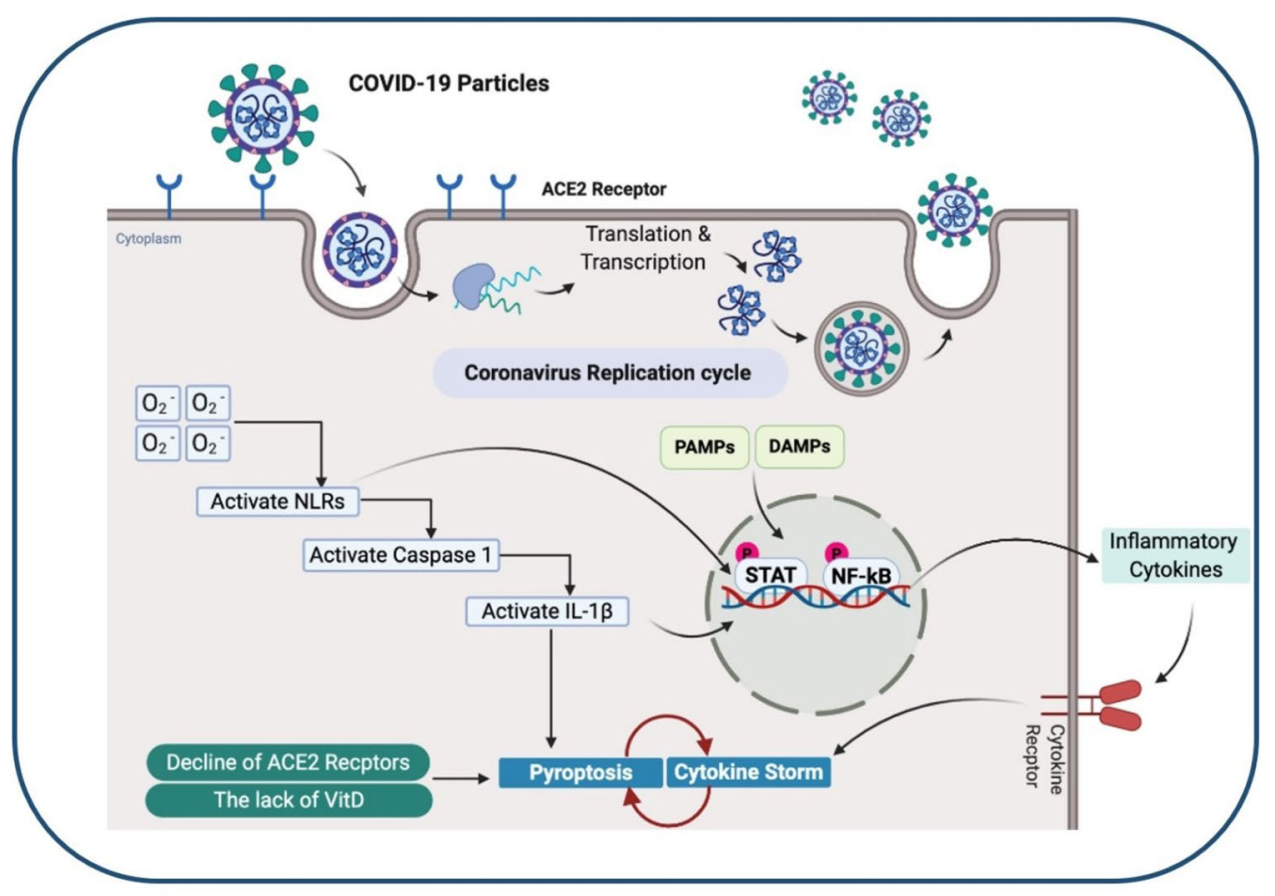

Fig. 3 Induction of cytokine storm in elderly or weak adults with COVID-19 in the late stage of infection. Several factors orchestrate induction of cytokine storm in some elderly adults with COVID19. First, decreased antioxidant capacity during aging together with excess ROS generation, increasing pro-inflammatory cytokine secretion during aging and induce mild inflammatory condition. Additionally, excess ROS generation during aging can activate NLRs, leading to generation of inflammasomes. The inflammasomes convert procaspase-1 (inactive form) to the active form of caspase-1. Subsequently, caspase- 1 converts pro-IL- $1 \beta$ to active IL-1 $\beta$. Excess release

\section{Anti-rheumatoid agents for the treatment of severe cases of COVID-19 infection}

It is accepted that cytokine storm is an important cause of multi-organ failure and death in the late stages of COVID-19 in elderly or weak adults [16]. Hence, early identification and appropriate treatment of the cytokine storm is critical for reducing the mortality of patients with COVID-19. Although several antiviral drugs are being actively tested, none has been specifically approved for COVID-19 [21]. It has been proposed that immunosuppression, such as anti-rheumatoid agents may be beneficial to reduce cytokine storm and mortality in patients with a severe infection of COVID-19. However, the using an immunosuppressant on these patients should be carefully considered, because anti-viral immunity is required to recover from COVID-19 [2]. Here, we are going to summarize the existing immunotherapeutic strategies for severe COVID-19 patients and related diseases such as SARS-CoV-1 and MERS-CoV. We also review both their therapeutic effects and side effects in related-disease of of IL-1 $\beta$ is associated with pyroptosis and cytokine storm in elderly adults. Second, the decline of ACE2 receptor expression and vitamin D deficiency in aged-subjects can increase secretion of pro-inflammatory cytokines in elderly adults. Finally, pro-inflammatory cytokines can increase their own generation via an autocrine pathway. ACE2 angiotensin converting enzyme, $I L$ interleukin, PAMPs pathogenassociated molecular patterns, DAMPs danger-associated molecular patterns, $N L R$ nucleotide-binding domain leucine-rich repeat, $N F-\kappa B$ nuclear factor $\kappa \mathrm{B}, S T A T$ signal transducer and activator of transcription, Vit $D$ vitamin D. Figure created using BioRender software

CoVs family, particularly novel COVID-19, from 2003 till now.

\section{IL-1 inhibitors}

IL-1 is a highly active pro-inflammatory cytokine that playing a dominant role in a cytokine storm and pyroptosis in COVID-19 patients. IL-1 families are major mediators of innate immune reactions [22]. There are two related but distinct IL- 1 cytokine, which is IL- $1 \alpha$ and IL- $1 \beta$. Each IL-1 binds to the same receptor, IL-1 receptor type 1 (IL-1RI). The cytosolic segment of IL-1RI contains the Toll-L-1-receptor domain [23]. The IL-1 $\alpha$ precursor is constitutively expressed in healthy individual cells, including platelets, keratinocytes, epithelial cells, liver, lung, and kidney [24]. However, IL-1 $\beta$ is not expressed in healthy individuals. It is expressed in a limited number of cells, including monocytes, macrophages, as well as antigen-presenting cells. Several factors can induce IL-1 $\beta$ expression, including microbial pathogens, TNF, IL-18, IL-1 $\alpha$, or even IL- $1 \beta$ itself [25]. 
The interaction of both types of IL-1 to IL-1RI can initiate phosphorylation and ubiquitination events, including activation of NF- $\mathrm{kB}$, the JNK, as well as p38-MAPK signaling pathways. Subsequently, IL-1 triggers a cascade of inflammatory mediators [22, 26-28]. Monotherapy blocking IL-1 activity in auto-inflammatory diseases (such as rheumatoid arthritis) improved the severity of the disease [2]. Among 11 members of the IL- 1 family, IL-1 $\beta$ has emerged as a therapeutic target for the treatment of auto-inflammatory diseases $[22,23]$. There are no organ toxicities or gastrointestinal disturbances with specific IL- $1 \beta$-targeting agents such as anakinra [23]. Previous reports demonstrated that IL- $1 \beta$ levels increased in patients with SARS-CoV1 and MERS-CoV infection [29]. Recent evidence to COVID-19 supports that a high level of IL-1 is related to the severity of disease [30]. Therefore, a specific IL-1-targeting agent likely is a reasonable approach for the treatment of hyper-inflammation in these patients [2]. Anakinra is a recombinant IL-1R antagonist, thereby inhibits the pro-inflammatory effects of IL-1. It can block the binding of both IL- $1 \alpha$ and IL-1 $\beta$ to IL-1R [31]. Anakinra is approved for several hyper-inflammatory conditions, including Macrophage Activation Syndrome (MAS), hemophagocytic lymphohistiocytosis (HLH), rheumatoid arthritis, Still's disease, and cryopyrin-associated periodic syndrome [32]. Monteagudo and colleagues (2020) reported the therapeutic effects of anakinra in five adult patients with sHLH /MAS. They reported that anakinra injection (IV infusions up to $2400 \mathrm{mg}$ /day) reduced cytokine storm and subsequent clinical improvement in sHLH/MAS patients [33]. The recommended subcutaneous dose of anakinra ranges from 100 to $200 \mathrm{mg}$ daily to $100 \mathrm{mg}$ three times weekly in adults. According to the data of phase 3 randomized clinical trial, anakinra was found to be beneficial in patients with severe sepsis with hyper-inflammation without markedly side effects [34]. However, patients with kidney insufficiency required dose adjustment (it should be given in every 2 days) [31]. Furthermore, reaction at the site of injection and infection was observed in chronic anakinra therapy [35]. Among anti-cytokine therapies, anakinra is appealing in this situation because it has a relatively short half-life (4-6 h) and high bioavailability (95\%) in the subcutaneous route. Thus, the dose and route of administration of that being considered with both intravenous and subcutaneous routes [32, 36, 37]. Pharmacokinetics studies revealed that the subcutaneous route likely induces adequate and consistent plasma concentrations of anakinra in different chronic inflammatory conditions [38]. Recently, several trials of anakinra reported the efficacy and safety of anakinra (dosage range between 100 and $300 \mathrm{mg}$ via both subcutaneous and intravenous injections) in reducing hyper-inflammation and pneumonia in patients with COVID-19 [36, 39]. Filocamo and colleagues in a case report study revealed that one patient (50-year-old men) with severe COVID-19 successfully treated with anakinra. They started a routine medication for the patient on day 1 after admission, including anti-viral therapy lopinavir/ritonavir plus hydroxychloroquin. But, on day 10 after hospital admission, his conditions worsened, and the ferritin levels observed more than $3000 \mathrm{ng} / \mathrm{m}$. At this moment, anakinra (200 mg intravenously) started and followed by $100 \mathrm{mg}$ every $6 \mathrm{~h}$ subcutaneously and all other routine medication was interrupted. On day 13 , the respiratory function of the patient improved and on day 18, the patient was discharged from the ICU [40]. Aouba and colleagues (2020) target the hyper-inflammatory pathway with anakinra in moderate to severe COVID-19 patients with pneumonia. They reported that anakinra therapy prevents mechanical ventilation and decreases serum inflammatory markers in nine patients with COVID-19, with no toxicity [36]. In anakinra therapy, it is important to target treatment to patients considered to have hyper-inflammation. Because in the wrong patient group (without hyper-inflammation), it can target beneficial inflammation [39]. Increasing serum CRP, ferritin and IL-6 levels and worsening lymphopenia are highly specific to hyper-inflammation in severe cases of COVID-19 [41]. The second blocker of IL is canakinumab, which is a high affinity, monoclonal anti-IL-1 $\beta$ antibody. Following subcutaneous injection of $150 \mathrm{mg}$, peak serum concentration is achieved in 7 days. The recommended dose interval is every 2 months [4]. Ucciferri and colleagues did a retrospective analysis of ten COVID-19 patients (with bilateral pneumonia, hyper-inflammation, respiratory failure, as well as high serum $\mathrm{CRP} \geq 50 \mathrm{mg} / \mathrm{L}$, and respiratory failure) in Italy. They reported that canakinumab therapy (subcutaneously in a single $300 \mathrm{mg}$ dose), in combination with routine medication (hydroxychloroquine and lopinavir-ritonavir), associated with a rapid reduction in the hyperinflammatory condition and an improvement in oxygenation. Additionally, they observed that anakinumab was well tolerated, with no recorded injection site reactions, infection, or side-effects [42]. Furthermore, Wang and colleagues recommend targeting the cytokine storm pathway by anti-IL-1 $\beta$ agents (canakinumab), anti-IL-1R agents (anakinra), as well as TNF- $\alpha$ antagonist (etanercept, infliximab) can suppress the cytokine-associated cardiovascular impairment in the COVID-19 [43]. The third blocker of IL-1 is rilonacept, which is a recombinant soluble IL-1 receptor. It is approved by the FDA for the treatment of several inflammatory diseases, including Cryopyrin-associated periodic syndromes (CAPS) [44]. It is reported that the half-life of rilonacept is ranging between 6.3 and 8.6 days. The recommended dose is $160 \mathrm{mg}$ in CAPS patients for inhibition of hyper-inflammation [45]. Clinical trials revealed a marked reduction in serum CRP level (pre-treatment baseline value $=22 \mathrm{mg} / \mathrm{L}$, week six $=2 \mathrm{mg} / \mathrm{L}$ ) in patients with CAPS [46]. The major side effects of rilonacept therapy in patients with CAPS were reactions at injection-site, upper respiratory tract infections, 
sinusitis, cough, hypoesthesia, nausea, diarrhea, stomach discomfort, and urinary tract infections [44]. At the moment, the present review is being written, the use of rilonacept for severe COVID-19 infection has not been reported yet.

\section{IL-6 inhibitors}

Human pleiotropic cytokine IL-6 is a $26 \mathrm{kDa}$ protein and consisted of 212 amino acids. IL-6 stimulates hepatocytes to induce the synthesis of CRP, fibrinogen, haptoglobin, as well as alpha-1-antichymotrypsin [47]. The IL-6 is a key pro-inflammatory marker that has an important role in cytokine storm in COVID-19 patients. Ample pieces of evidence reported that excess IL-6 levels could be used as an indicator for the fast prognosis and poor outcome in COVID-19 patients [1, 21, 48]. In 1 study of 102 mild and 21 severe patients with confirmed COVID-19, the severe group has a markedly higher concentration of IL-6 than the mild group [49]. IL- 6 can be generated by both innate immune effectors (such as macrophages, dendritic cells, and fibroblast) and by a cell-mediated immune effector (such as $\mathrm{T}$ - and B-cells) [50, 51]. It should be noted, on one hand, increased IL-6 serum level in some infectious diseases such as influenza suppressed influenza-induced inflammation and improved lung injury [52]. In another hand, extreme elevation of IL-6 serum level in severe cases of COVID-19 can induce the hyper-inflammatory condition (or cytokine storm) in response to COVID-19 particles [50]. Surprisingly, it is reported that SARS-CoV-1 can induce a greater IL-6 level when compared to the influenza-A virus [53]. Similarly, some studies identified the association of extreme elevation of IL-6 serum level with mortality of COVID-19 [41, 54]. All of these mentioned studies pointing to a possible critical contribution of IL-6 in COVID-19. Therefore, the use of IL-6 blockers likely could be a strategy for the management of the cytokine storm in the severe cases of COVID-19 [1].

IL-6 signals are transmitted via two different types of receptors; trance-membrane receptor (mIL-6R; $80 \mathrm{kDa}$ ) and soluble-bound receptor (sIL-6R; $55 \mathrm{kDa}$ ). These two different types of receptors can initiate different up-stream signaling pathways; the classic signaling pathway is mediated by the mIL-6R and trans-signaling is mediated by sIL-6R [55, 56]. The mIL-6R is composed of two different subunits, an alpha subunit that produces ligand specificity for IL-6 and beta subunit glycoprotein 130 (gp130). The expression of mIL-6R is mostly in leukocytes and hepatocytes [47]. The binding of IL-6 to its alpha subunit triggers dimerization of the beta subunit gp130 and alpha subunit, and subsequent activation of the intracellular downstream signaling pathway, including activation of Janus Kinase (JAK)/STAT, and ras/ MAP kinase pathways [55, 56]. Additionally, the mIL-6R protein can lyse by a metalloprotease activity (such as protease ADAM17) and convert to a soluble form of IL-6R in the circulation [57-59]. Therefore, IL-6 can initiate intracellular up-stream pathways via binding to either the mIL6R (classical pathway) or sIL-6R (trans-signaling pathway) [60]. It is reported that classic and trans-signaling pathways of IL-6 have different effects on the body. Indeed, in the trans-signaling, the IL- 6 and sIL-6R complexes can subsequently bind to membrane-bound gp 130 proteins and induce trans-signaling [61]. Because all cells ubiquitously express gp130 proteins, whereas only a few cells in the human body express mIL-6R. So, it seems that all cells act as a target cell for IL-6 in the trans-pathway [61-63]. Therefore, it is proposed that the trans-signaling pathway of IL- 6 is involved in the hyper-inflammation [64]. In contrast, it is reported that the classic-signaling pathway of IL-6 has protective effects [65]. Both classic-signaling and trans-signaling pathways are gp130-mediated and activate the same intracellular pathways [47]. In the following, we are going to review the studies that have used IL- 6 blockers as a strategy for the management of the cytokine storm in the severe cases of COVID-19. One of the most important anti-IL-6 cytokines is Tocilizumab. Tocilizumab, a recombinant humanized anti-interleukin-6 receptor monoclonal antibody, can bind to both the mIL-6R and sIL-6R, blocking both classic and trans-signaling pathway of IL-6 [50]. Tocilizumab is currently approved for the treatment of hyper-cytokinemia in autoimmune diseases, such as rheumatoid arthritis, juvenile idiopathic arthritis, and Crohn's disease [2, 66, 67]. However, there are many studies evaluating the therapeutic effects of tocilizumab as an alternative treatment for COVID-19 patients with a high risk of cytokine storms recently. The inclusion criteria for Tocilizumab administration in COVID-19 patients in Italy and other countries are high levels of IL-6 (more than $40 \mathrm{pg} / \mathrm{ml}$ ), D-Dimer, ferritin, as well as progressive increasingly level of fibrinogen [50]. A recent study by $\mathrm{Xu}$ and colleagues assess the therapeutic effects and efficacy of tocilizumab in severe cases of COVID-19. They observed that 5 days after administration of tocilizumab, $75 \%$ of patients (15/ 20 patients) had lowered oxygen intake. Lung opacity decreased in chest CT scans in 90.5\% (19/20 patients). The lymphocyte number and abnormal elevated C-reactive protein returned to normal values in $52.6 \%$ of patients (10/19 patients) and $84.2 \%$ of patients (16/19 patients), respectively. No obvious side effects were observed in all patients [68]. Additionally, Luo and colleges in 2020 reported that tocilizumab therapy suppressed the high level of CRP in the majority of patients with COVID19 rapidly (11/15 patients). Furthermore, they observed that serum IL-6 levels decreased after tocilizumab therapy in ten patients. They suggested that in the most severe and deadly cases of patients with excess serum IL-6 level, the repeated dose of the tocilizumab is recommended [69]. Furthermore, Mihai and colleges in 2020 reported that tocilizumab 
therapy in a COVID-19 patient (a 57-year-old woman) with insulin-dependent type 2 diabetes mellitus and systemic sclerosis leading to good control of both arthritis and respiratory symptoms. High-resolution CT imaging was observed after tocilizumab therapy. Tocilizumab was started with $8 \mathrm{mg} / \mathrm{kg}$ body weight (intravenously) and continued at 5 -week intervals [70]. Fontana and colleges in 2020 also in a case-report study in Italy revealed that a single administration of tocilizumab in combination with hydroxychloroquine successfully treated COVID-19 pneumonia in a kidney transplant recipient (61-year-old). Furthermore, the patient did not require mechanical ventilation after tocilizumab therapy [71]. The recommended dose of tocilizumab for the treatment of patients with severe COVID-19 is $8 \mathrm{mg} / \mathrm{kg}$ (400 mg, IV infusion) for a single dose to suppress cytokine storm. However, for patients with poor efficacy of the single dose of tocilizumab, it divided two doses by $12-24 \mathrm{~h}$ intervals (maximum dose $800 \mathrm{mg}$ ). The infusion time is more than $1 \mathrm{~h} \mathrm{[72].} \mathrm{Since} \mathrm{the} \mathrm{tocilizumab} \mathrm{introduction} \mathrm{for} \mathrm{the}$ treatment of a variety of autoimmune diseases, it has shown good efficacy and safety in patients [73, 74]. However, general infections, hepatotoxicity, hypertriglyceridemia, as well as diverticulitis are the major side-effects of tocilizumab treatment [75]. Hence, it seems that tocilizumab therapy can improve respiratory function in severe and critical cases of COVID-19. However, while tocilizumab is a promising agent against COVID-19, clinicians should notice that likely blocking IL-6 could interfere with the clearance of COVID19 particles. Tocilizumab can suppress both the classicsignaling pathway (protective pathway) and trans-signaling pathway (hyper-inflammatory pathway) of IL-6 [2]. Hoge and colleagues in 2013 reported selective inhibition of IL-6 trans-signaling by application of $\operatorname{sgp} 130 \mathrm{Fc}$, a fusion protein of the gp130 with the Fc portion of a human immunoglobulin antibody, did not impair control of Listeria monocytogenes infection in mice. However, they showed that application of neutralizing anti-IL-6 antibody result in increased bacterial titers. They suggested that classic signaling has protective effects against bacterial infection [76]. Similarly, it is reported that the application of recombinant soluble IL-6R, mimic the trans-signaling of IL-6, in deficient mice restores the lethal outcome of malaria. However, blockade of IL- 6 trans-signaling by application of sgp $130 \mathrm{Fc}$ protein in wild-type mice leads to a $40 \%$ survival rate [77]. Therefore, it is suggested that the use of the sgp $130 \mathrm{Fc}$ protein can suppress the pro-inflammatory effects of IL- 6 via the transsignaling pathway and preserve the anti-inflammatory effects of IL-6 via the classic-signaling pathway [78]. However, there is no study in the literature about the therapeutic effects of sgp130Fc protein in COVID-19 patients yet. Another monoclonal antibody of IL-6 is siltuximab. The siltuximab forms high-affinity complexes with both soluble and membrane-bound IL-6R [79]. Administration of siltuximab can inhibit the dimerization of IL-6R with gp130 on the cell surface, and subsequent activation of the downstream signaling. Additionally, siltuximab forms high-affinity complexes with soluble forms of human IL-6, naturalizing IL-6 activity $[1,80]$. Siltuximab is approved by the Food and Drug Administration of the USA, for the treatment of Castleman's disease, which is a rare lymphoproliferative disorder driven by the deregulated production of IL-6. The recommended dose of siltuximab is $11 \mathrm{mg} / \mathrm{kg}$ (intravenous infusion) for $1 \mathrm{~h}$ every 3 weeks. However, the dosing interval may be extended to every 6 weeks in some cases. Furthermore, it is reported that patients with kidney insufficiency do not require any dose adjustment compared with patients with normal kidney function [66]. Several shreds of evidence identified the therapeutic effects of siltuximab in a single dose of $11 \mathrm{mg} / \mathrm{kg}$ in severe forms of COVID-19 with a high level of IL-6. For example, in a retrospective study, Gritti and colleagues in 2020 investigated the therapeutic effects of intravenous application of siltuximab (at a dose ranging between 700 and $1200 \mathrm{mg}$; median $900 \mathrm{mg}$, within 2 days) in 21 patients with COVID-19 who developed ARDS (confirmed by clinical and radiological assessment) in Italy. The median age of patients was 64 years. All 21 patients required ventilation by continuous positive airway pressure or noninvasive ventilation. All patients follow-up for 8 daysafter siltuximab administration. Their data analysis identified that siltuximab reduced serum CRP levels to within the normal range in 16 patients. Additionally, 33\% of patients experienced an improvement in their condition with a reduced need for ventilation, $43 \%$ of patients experienced a stabilizing of their condition, and $24 \%$ of patients experienced a worsening of their condition and required intubation. Of those patients who experienced a worsening in their condition, one patient died, and one patient developed a cerebrovascular event [81]. Palanques-Pastor and colleagues in a short report identified that siltuximab could be considered as a therapeutic strategy for severe cases of COVID-19 with high IL-6 levels [1]. Side effects and complications of siltuximab were reported in an open-label extension analysis of a phase 1 trial and a phase 2 trial by van Rhee and colleagues in 2020 in 60 patients with multicentric Castleman disease. The most common side effects in their study were hypertension $(8 / 60 ; 13 \%)$, fatigue $(5 / 60 ; 8 \%)$, nausea $(4 / 60$; $7 \%)$, neutropenia $(4 / 60 ; 7 \%)$, infection $(25 / 60 ; 42 \%)$, as well as vomiting $(3 / 60 ; 5 \%)$, and no deaths were reported [82]. The maximum tolerated dose of siltuximab was reported $100 \mathrm{mg}$ twice weekly in Castleman's disease [66]. It should be noted that an increased level of IL-6 in some immune disorders, including COVID-19, can reduce the activity of cytochrome P450 [83]. Therefore, practitioners should be noted that if the activity of cytochrome $\mathrm{P} 450$ previously decreased in COVID-19 condition (by elevated IL-6), then administration of siltuximab may lead to increased 
metabolism, drugs that use the cytochrome $\mathrm{P} 450$ pathway (such as warfarin) [66]. IL-6 is also known to induce hepcidin production, therefore hepcidin concentrations are also affected by siltuximab administration, with a median of $47 \%$ decrease in hepcidin levels at day 8 of siltuximab treatment [84]. Since siltuximab has a high affinity to form complexes with the IL-6 and neutralizes the activity of IL-6. So its efficacy cannot be measured by evaluating the serum IL-6 level. Indeed, this effect of siltuximab interferes with the availability of IL-6 clinical test results. However, evaluation of CRP level can be used as a good marker for the serum IL-6 activity after siltuximab therapy in COVID-19 [85]. Maximum suppression of CRP level was observed at dose $12 \mathrm{mg} / \mathrm{kg}$ of siltuximab every 3 weeks [84]. Because the half-life of siltuximab is $16.3 \pm 4.2$ days [80] and the COVID-19 is an acute process, it is reported that a single dose would be sufficient for down-regulation of IL-6 [1, 81]. Another anti-IL-6 compound is sarilumab, which is a human monoclonal antibody directed against the alpha subunit of the IL-6R. Like tocilizumab, it binds specifically to both sIL-6R $\alpha$ and mIL-6R $\alpha$. Benucci and colleagues in 2020 describe the therapeutic effects of sarilumab in 8 patients with COVID-19 (mean age 62 years; six men and two women) hospitalized in San Giovanni di Dio Hospital in Florence, Italy. They added sarilumab $(400 \mathrm{mg}$; for a $1 \mathrm{~h}$ intravenous infusion) to routine medication of patients (hydroxychloroquine $400 \mathrm{mg}$, azithromycin $500 \mathrm{mg}$, darunavir $800 \mathrm{mg}$, cobicistat $150 \mathrm{mg}$, enoxaparin $100 \mathrm{U} / \mathrm{Kg}$ ). They observed that early treatment with sarilumab improved respiratory function and oxygenation and discharge from hospital in all patients. But, one patient (83-year-old patient) had no improvement in lung function and died 13 days after hospitalization [86]. The therapeutic effects of sarilumab in COVID-19 are being explored in several clinical studies, including "Evaluation of the efficacy and safety of sarilumab in hospitalized patients with COVID-19", "Treatment of moderate to severe coronavirus disease in hospitalized patients" and "Sarilumab COVID-19". Although, both serum IL-6 and IL-1 $\beta$ levels are increased in COVID-19 patients, however, it is far from clear whether one cytokine should be targeted before another. The various ongoing clinical studies will hopefully provide the appropriate timing of immunosuppressants administration in COVID-19.

\section{Type I and II interferons (IFNs)}

Interferons (IFNs) are a kind of cytokines and released by host cells in response to several pathogens, including bacteria, viruses, as well as tumor cells [87]. Based on their immunomodulatory, anti-viral, and anti-proliferative effects, the IFNs are a strong tool in the host cells against viral or bacterial infection and cancer ([88]. Today, three types of
IFNs are characterized, including type I IFNs, type II IFNs and type III IFNs [89]. Among them, type I IFNs and type II IFNs are well studied. Type I IFNs consist of a group of similar cytokines and include 12 IFN- $\alpha$ subtypes, IFN- $\beta$, IFN- $\varepsilon$, IFN- $\kappa$, IFN- $\omega$, IFN- $\delta$, IFN- $\zeta$, and IFN- $\tau[90,91]$. All of the cytokines in the type I IFNs family use the same receptor, which is the type I IFN receptor (IFNAR). IFNAR is present at the plasma membrane in most cell types. The interaction of IFNs with IFNAR induces the activation of the associated tyrosine kinases, Tyk2 and Jak1. Then, the activity of Tyk2 and Jak1 leads to phosphorylation of STAT2/STAT1, which forms a complex with IRF9, known as the IFN-stimulated gene factor 3 (ISGF3) [90]. Additionally, type I IFNs can also induce phosphorylation of STAT3/ STAT4/STAT5/STAT6, which are then activated Rap1, CrkL, Map kinases, IRS-1,2, Vav, RAC1, as well as PI3kinase signal transduction pathways. Furthermore, it is reported that the type I IFNs can induce IRF3/NFkb activation, and IRF7 phosphorylation, leading to a positive feedback loop of increasing type I IFN generation [92]. Type II IFN (or IFN- $\gamma$ ) is predominantly generated by natural killer cells during the innate immune response against viral infection [93]. They bind to the IFN- $\gamma$ receptor (IFNGR). The interaction of type II IFN with the IFNGR leads to activation of JAK1 and JAK2, leading to phosphorylation of STAT1. However, it is reported that type II IFN can also induce phosphorylation of STAT4, which is activated Erk1/2, Pyk2, and CrkL signaling pathways [94]. Type III IFNs is consist of four distinct subtypes of interferon $\lambda$, IFN $\lambda 1-4$ in human $[95,96]$. Based on IFNs immunomodulatory properties, IFN-I has been used in the treatment of several inflammatory diseases such as multiple sclerosis for more than 20 years. However, the therapeutic effect of IFN $\beta$ therapy in patients with multiple sclerosis is still debated. Because IFN $\beta$ therapy can down-regulate the major histocompatibility complex (MHC) class II expression on antigen-presenting cells, IL-10 secretion, as well as the inhibition of T-cell migration [97]. Furthermore, based on IFNs anti-viral properties, type I IFNs are used in the treatment of SARS, MERS-CoV, and COVID-19 infection [98-100]. Although, IFN therapy improved respiratory function in patients with MERS-CoV and SARS infection, however, review of human clinical studies identified that it generally failed to markedly improve the disease in patients with SARS and MERS-CoV [99, 101, 102]. For example, Zhao and colleagues in 2003 reported that IFN $\alpha$ in combination with fluoroquinolone/ azithromycin was inconclusive in patients with SARS infection and patients had significant mortality [103]. Additionally, Omrani and colleagues in 2014 analyzed the therapeutic effects of pegylated IFN $\alpha$-2a therapy (180 $\mu \mathrm{g}$ per week for 2 weeks) in combination with ribavirin in 20 patients with MERS-CoV infection. They reported the loss of a significant survival difference between the treatment and control 
groups. Indeed, IFN $\alpha-2 \mathrm{a} /$ ribavirin therapy delayed mortality without decreasing it [104]. Sheahan and colleagues in 2020 also reported that a combination of prophylactic IFN $\beta$ therapy with lopinavir/ritonavir against MERS-CoV improved respiratory function, but did not markedly reduce virus replication or lung pathology severity in mice [102]. Similarly, Arabi and colleagues in 2017 reported that IFNs therapy (IFN $\alpha-2 a$, IFN $\alpha-2 b$, and IFN $\beta$ ) in combination with ribavirin was inconclusive in patients with MERS infection [101]. Furthermore, Scagnolari and colleagues in 2007 reported that the combination of type I IFNs (IFN- $\alpha$ and IFN- $\beta$ ) and IFN- $\gamma$ application, inhibited synergistically SARS-CoV1 replication in Vero cells. They suggested that SARS-CoV, although only moderately sensitive to the antiviral action of the individual types of IFN, it is highly sensitive to a combination of type I and II IFNs [99]. However, there are conflicting articles in favor of the therapeutic effects of the IFNs therapy in patients with SARS-CoV1 and SARS-CoV2. For example, Loutfy and colleagues in 2003 reported that the combination of IFN alfacon-1 with corticosteroids increased oxygen saturation, improved lung abnormalities, as well as decreased creatine kinase levels in patients with SARS-CoV1 infection [98]. Additionally, it is reported that IFN therapy has positive and efficient in patients only if they lacked comorbidities [100]. The first possible explanation of inconsistencies between studies is the diversity of INFs subtype. The different INFs subtype can induce different responses, despite signaling through the same receptor. It is likely that several factors are involved in different responses of INFs, including binding affinity, duration of binding, as well as the number of surface receptors [105]. James and colleagues in 2007 reported that pre-treatment of influenza-infected mice with the same dose of different type I IFN subtypes (IFN- $\alpha 1$, IFN- $\alpha 5$, and IFN- $\alpha 6$ ) leading to different antiviral efficacy of IFNs on levels of virus replication. They reported that IFN- $\alpha 5$ and IFN- $\alpha 6$ having more suppressive effects on the viral load than IFN$\alpha 1$ [106]. In another scenario, Scagnolari and colleagues (2004) compared the antiviral effect of different IFNs on SARS-CoV1 replication in the epithelial kidney monkey Vero cell line. They revealed that SARS-CoV1 grown in Vero cells is moderately sensitive to interferon-beta and only weakly sensitive to interferon-alpha and interferon-gamma. They also reported that simultaneous incubation of Vero cells with interferon-beta and interferon-gamma indicated that they may act synergistically against SARS-CoV1 replication [107]. Generally, it is reported that IFN $\beta-1 b$ or IFN $\beta-1 \mathrm{a}$ is a more potent inhibitor of SARS-CoV1 and MERS-CoV infection than IFN- $\alpha[108,109]$. Since, intravenous injection of IFN $\beta 1$ can up-regulate CD73 cell expression in pulmonary endothelial cells, leading to a rise in the generation of anti-inflammatory adenosine. So, this fact can be associated with the protective function of IFN $\beta 1$ in the lung [110]. The second possible explanation is the presence of anti-interferon proteins of SARS-CoV and MERS-CoV, including Orf3b and Orf6 proteins. These proteins can disrupt the IFNs signaling pathway. The anti-interferon Orf3b protein can suppress the phosphorylation of IRF3, which is a protein involved in the activation of the IFN expression [15]. Additionally, the anti-interferon Orf6 protein can suppress the translocation of STAT1 to the nucleus [100]. However, Lokugamage and colleagues in 2020 examined the homology between SARS-CoV and novel COVID-19 in viral proteins. They revealed that these two important antiinterferon proteins, including open reading frame (ORF) $3 \mathrm{~b}$ and ORF6 proteins, may not maintain equivalent function in COVID-19 infection [111]. Their results also identified that COVID-19 particles are much more sensitive type I IFN pretreatment. Supporting this hypothesis, Payandemehr and colleagues in 2020 were shown IFN beta-1a in combination with antiviral and hydroxychloroquine treatment markedly improved respiratory function in 20 patients with COVID-19 [112]. Hence, it is suggested that COVID-19 infection is substantially more sensitive to IFNs therapy than SARSCoV or MERS-CoV. COVID-19 viral replication is not entirely suppressed by IFNs therapy [111]. The third possible explanation of inconsistencies between studies is the diversity of the timing of IFNs administration. Channappanavar and colleagues in 2019 identified that administration of IFN-I shortly after infection (before virus titers peak) have protective effects in mice with MERS coronavirus infection. In contrast, IFN failed to inhibit viral replication and had side effects when administered later delayed. They suggested that the timing of the IFN-I response and maximal virus replication is an important factor in determining outcomes in infected mice with MERS infection [113]. Generally, it is suggested that combination therapy of different types of INFs may have positive effects in the treatment of SARS$\mathrm{CoV}$ infections. For example, Scagnolari andcolleagues in 2007 reported that the combination of type I IFNs (IFN- $\alpha$ or $-\beta)$ and IFN- $\gamma$ application, inhibited synergistically SARS$\mathrm{CoV}$ replication in Vero cells. They suggested that SARS$\mathrm{CoV}$, although only moderately sensitive to the antiviral action of the individual types of IFN. However, it is highly sensitive to a combination of type I and II IFNs [99]. Altogether, IFN $\beta 1$ may account for a safe and easy to upscale treatment against COVID-19 in the early stages of infection. Further assessment is recommended.

\section{JAK/STAT inhibitors}

The JAK family belongs to the family of receptor-associated tyrosine kinases (TYK). They include JAK1, JAK2, JAK3, and TYK2. JAK1, 2, and TYK2 are found ubiquitously, whereas JAK3 likely exerts an important role 
in hematopoiesis and lymphocyte function [114]. JAK family can transmit signals from many pro-inflammatory cytokines to phosphorylate and activate STAT in response to exogenous pathogens. JAK/STAT signaling pathway is an important signaling pathway in response to exogenous pathogens of the immune system, leading to the high-level generation of pro-inflammatory cytokines. The human STAT family consists of seven types of STAT, including STAT1-4, STAT5A, STAT5B, and SATAT6. The JAK/ STAT signaling pathway is also regulated by negative regulators, including the suppressors of cytokine signaling (SOCS) proteins. Many of the cytokines involved in COVID-19 use JAK/STAT signaling pathway. So, it seems that JAK inhibitors can be an attractive therapeutic strategy for the treatment of cytokine storm in COVID19 [115]. Two studies with therapeutic effects of baricitinib on COVID-19 are ongoing (NCT04320277 and NCT04321993). Currently, JAK inhibitors are used in the treatment of chronic inflammatory diseases such as rheumatoid arthritis [116]. Since signal transduction in COVID-19 host cells and many immune cells is through the JAK2/STAT signaling pathway. Therefore, targeting JAK/STAT signaling pathway can improve the treatment of COVID-19 [114]. Furthermore, JAK inhibitors may suppress the IFNs signaling pathway, because IFNs use the JAK/STAT signaling pathway. Cameron et al. conducted a microarray study, which established that patients with SARS-CoV-1 who were discharged from hospitals showed low IFN- $\alpha$ and IFN-y signaling while IFN- $\alpha$ and IFN-y signaling was evident in patients who died [117]. Baricitinib is a compound that selectively inhibits the kinase activity of JAK1 and JAK2, and not JAK3 [118]. Baricitinib is approved by the European Medicines Agency for the treatment of rheumatoid arthritis and psoriatic arthritis [119]. Richardson and colleagues reported that baricitinib therapy improved respiratory failure and cytokine storm in COVID-19 patients via suppressing JAK1 and JAK2 signaling pathways. Furthermore, these researchers identified that baricitinib therapy can reduce the COVID-19 particle entry in human lung host cells via two mechanisms; (1) inhibiting adaptor associated protein kinase 1 (AAK1), and (2) binding to the cyclin G-associated kinase (GAK). It is believed that AAK1 and GAK are involved in the endocytosis of COVID-19 particles (viral entry). Therefore, they suggested that baricitinib therapy not only interrupts the entry and intracellular assembly of COVID19 particles into the human host cells via disruption of AAK1-GAK signaling, but it also decreased the cytokine storm in COVID-19 patients via suppressing JAK1 and JAK2 signaling pathway [120]. Additionally, baricitinib can decrease IL-6 and GM-CSF levels, which are important markers in triggering cytokine storm in COVID-19 [121]. Stebbing and colleagues revealed that three JAK inhibitors, including baricitinib, ruxolitinib, and fedratinib, had similar JAK inhibitor potencies. However, baricitinib has more affinity to AAK1 [122]. Therefore, it is likely that the immunosuppressive function of baricitinib is of benefit to the hyper-inflammatory condition in severe and deadly cases of COVID-19 with pneumonia [2]. Tofacitinib is another compound that inhibits the kinase activity of JAK1, JAK2 and JAK3. Since JAK3 is limited to cytokines using the common $\gamma$ chain family, tofacitinib can effectively block IL-2, IL-7, and IL-6 [114]. Contradictory with baricitinib, tofacitinib does not significantly inhibit AAK1 [123]. Tofacitinib therapy in rheumatoid arthritis decreased CRP level and erythrocyte sedimentation rates (ESR) [124]. The major side effects of tofacitinib therapy in patients with rheumatoid arthritis were increasing both low-density lipoprotein (LDL) and high-density lipoprotein (HDL) levels, and decreasing blood neutrophils [125]. Nevertheless, no treatment of COVID-19 with tofacitinib has been reported to date. A novel target in the JAK/STAT pathway against COVID-19 is inositol-requiring transmembrane kinase/endoribonuclease $1 \alpha$ enzyme (IRE1 $\alpha$ ). Ma and colleagues in 2018 reported that IRE1 $\alpha$ act as an endoplasmic reticulum stress sensor, leading to increased expression of negative regulators of JAK/STAT, suppressor of cytokine signaling (SOCS)-1 and SOCS-3 in response to $\mathrm{CoVs}$ transmissible gastroenteritis virus. Therefore, IRE1 $\alpha$ may be a novel target against COVID19 and requiring further studies [126]. At the moment the present review is being written, it has not been reported targeting IRE1 $\alpha$ to confirm its therapeutic effects in COVID-19 infection. Other JAK inhibitors, including ruxolitinib, memolitinib, oclacitinib, Fedratinib, Gandotinib, and pacritinib target both JAK1 and JAK2 which can potentially affect signaling pathways downstream of the receptors [127] may involve in COVID-19 development. Recently, Cao and colleagues demonstrated the efficacy of ruxolitinib in severe cases of COVID-19. They reported that patients receiving ruxolitinib had a faster clinical improvement as compared with the control group [128]. At least, 16 clinical trials currently underway evaluating ruxolitinib in severe cases of COVID-19 (NCT04377620, NCT04362137, NCT04338958, NCT04414098, NCT04348695, NCT04348071, NCT04403243, NCT04331665, NCT04366232, NCT04334044, NCT04374149, NCT04359290, NCT04361903, NCT04355793, NCT04337359, ChiCTR2000029580). Notably, all mentioned JAK/STAT inhibitors cannot discriminate infected host cells from healthy cells, which leads to potential side effects. Therefore, specific inhibition of the JAK/STAT signaling pathway in infected cells remains to be clarified. More studies are needed to clarify the efficacy of JAK/STAT inhibitor therapeutics on COVID- 19. 


\section{Convalescent plasma therapy}

Convalescent plasma, which is classic adoptive immunotherapy, was obtained from the recovered patient from endemic infectious diseases [129]. Immune globulin (also named gamma globulin) is prepared from plasma obtained from thousands of people representing a diverse antibody repertoire and is administered by intravenous routes (IVIg) [130]. IVIg has been used for the treatment of patients with autoimmune diseases, including multiple sclerosis, lupus, and idiopathic thrombocytopenic purpura. Furthermore, IVIg has also been used as an anti-infectious agent against viruses and bacteria in human and animal studies [129]. Mair-Jenkins and colleagues in 2015 review 27 studies of convalescent plasma in various respiratory infections. They identified that convalescent plasma therapy could decrease the mortality of patients [131]. IVIg may modulate the immune response via multiple mechanisms, including inhibiting various proinflammatory cytokines, blocking Fc-gamma receptors ( $\mathrm{Fc} \gamma \mathrm{Rs}$ ), as well as suppressing immune effectors such as Th1 and Th17 cells [129]. Hyperimmune globulin is produced from a convalescent plasma pool with high antibody levels against infectious particles. It is accepted that hyperimmune IVIg (hIVIg) have higher neutralizing antibody titers as compared with the convalescent plasma. Additionally, blood group matching is not required for the hIVIG [130]. Recently, convalescent plasma and hIVIg are being evaluated in trials as a therapeutic option for patients with COVID-19 infection. For the treatment of COVID-19 infection, IGg was administered in two doses of $250 \mathrm{~mL} 12 \mathrm{~h}$ apart. For example, Ahn and colleagues in 2020 in Korea revealed that transfusion of convalescent plasma in two COVID-19 patients with severe pneumonia causes a favorable outcome in both two patients [132]. Similarly, Shen and colleagues in 2020 reported a case study of five to severe cases of patients with COVID-19. All patients were receiving mechanical ventilation. Transfusion of convalescent plasma decreased viral loads and also increased neutralizing antibody titers (range, $40-60$ before and 80-320 on day 7 after transfusion) [133]. Additionally, Liu and colleagues in 2020 evaluated the effectiveness of convalescent plasma therapy in 39 severe cases of COVID-19 in New York City. They observed that the survival of patients improved in plasma recipients [134]. Overall, immunotherapy with immune $\mathrm{IgG}$ in combination with antiviral drugs could be used to treat COVID-19 infection. Nevertheless, the complication and side effects of convalescent plasma therapy in COVID-19 remains uncertain.

\section{Conclusion}

It is accepted that cytokine storm is a fatal outcome of COVID-19 in elderly or weak adults. Although the release of pro-inflammatory cytokines, as a host anti-viral response, is required for the clearance of COVID-19 particles, excessive activation of immune response and cytokine storm can induce multi-organ failure and death. There is no approved effective drug or vaccine for the treatment of novel COVID19. Immunosuppressant, such as anti-rheumatoid drugs, could be considered as a potential approach for the treatment of cytokine storm in severe cases of COVID-19 (Fig. 4). One possible limitation of immunosuppressants therapy is their inhibitory effects on host anti-viral immune response. So, the appropriate timing of immunosuppressants administration should be carefully considered. Unfortunately, there is not yet specific data on the appropriate timing of immunosuppressants therapy. One way to prevent the inhibition of host anti-viral immunity is to choose selective immunosuppressive drugs. The various ongoing clinical and experimental studies will hopefully provide the appropriate timing of immunosuppressants administration in COVID-19. 
Fig. 4 The targets of antirheumatoid agents in the host inflammatory pathway in COVID-19 infection. The IL-1, IL-6, and IFNs bind to their own receptors (IL-1RI, sIL-6R, IFNAR, respectively) and trigger specific signaling cascades to activate the generation of multiple cytokines. IL-1 inhibitors, IL-6 inhibitors, and JAK inhibitors (ruxolitinib, tofacitinib, baricitinib, peficitinib, fedratinib, and upadacitinib) can limit cytokine storm and hyperinflammation by suppressing these signaling cascades. $I L$ interleukin, IFN interferones, IFNAR type I IFNs receptor, $I S G F$ IFN-stimulated gene factor, $R$ receptor, $s I L-6 R$ soluble interleukin receptor, $J A K$ Janus kinase, STAT signal transducer and activator of transcription, $N F-\kappa B$ nuclear factor $\kappa \mathrm{B}$. Figure created using BioRender software

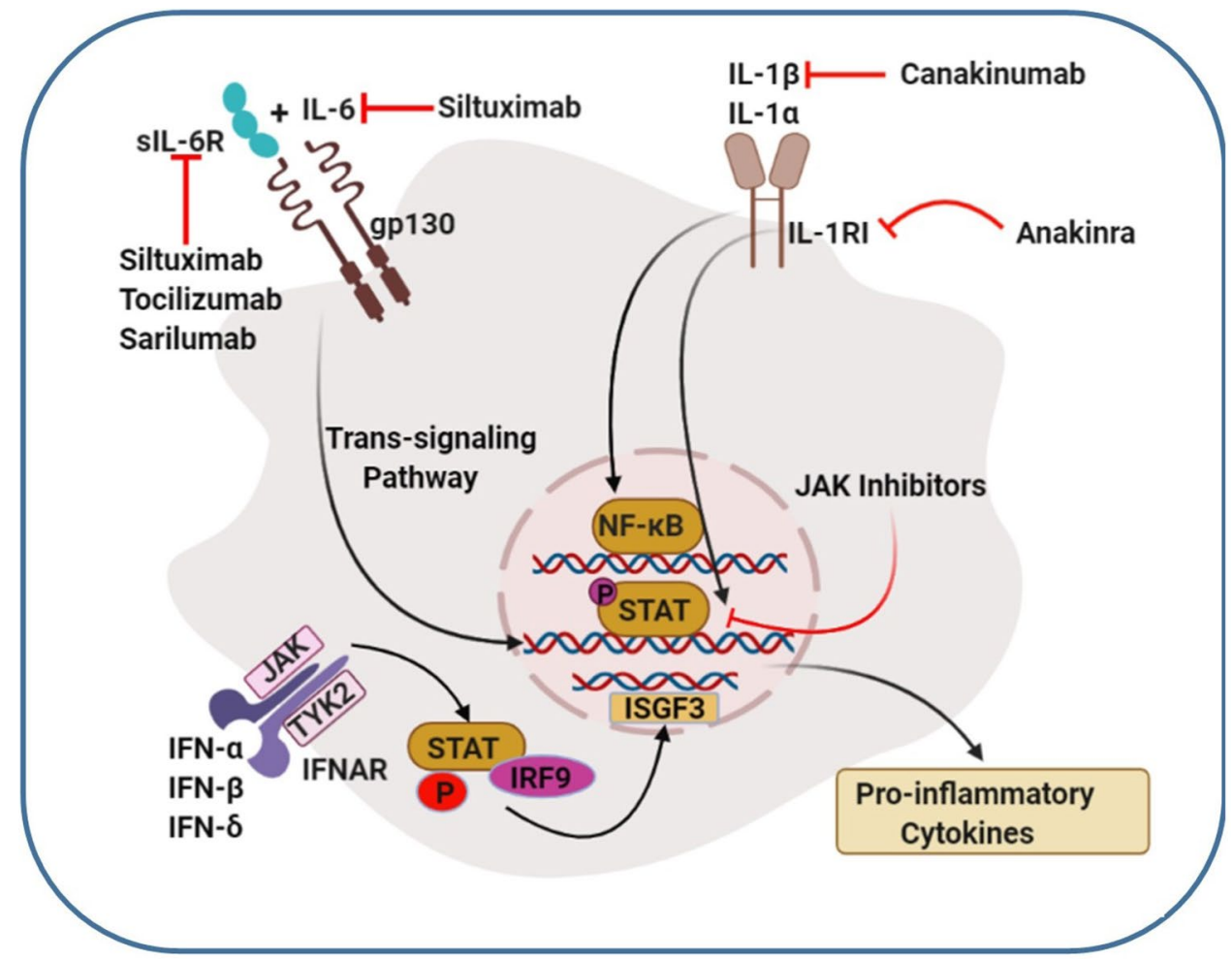

Acknowledgements This study was supported by Neuroscience Sciences Research Center, Baqiyatallah University of Medical Sciences, Tehran, Iran.

\section{Compliance with ethical standards}

Conflict of interest The authors declare no conflicts of interest.

\section{References}

1. Palanques-Pastor T, López-Briz E, Andrés JLP. Involvement of interleukin 6 in SARS-CoV-2 infection: siltuximab as a therapeutic option against COVID-19. Europ J Hosp Pharm. 2020;0:1-2.

2. Zhong J, Tang J, Ye C, Dong L. The immunology of COVID-19: is immune modulation an option for treatment? Lancet Rheumatol. 2020;2(7):428-36.

3. Song P, Li W, Xie J, Hou Y, You C. Cytokine Storm Induced by SARS-CoV-2. Clin Chim Acta. 2020;59:280-7.

4. Soy M, Keser G, Atagündüz P, Tabak F, Atagündüz I, Kayhan S. Cytokine storm in COVID-19: pathogenesis and overview of anti-inflammatory agents used in treatment. Clin Rheumatol. 2020;39:2085-94.

5. Ahmad I, Rathore FA. Neurological manifestations and complications of COVID-19: A literature review. J Clin Neurosci. 2020;77:8-12.

6. Toscano G, Palmerini F, Ravaglia S, Ruiz L, Invernizzi P, Cuzzoni MG, Franciotta D, Baldanti F, Daturi R, Postorino P, Cavallini A. Guillain-Barré syndrome associated with SARS-CoV-2. N Engl J Med. 2020;382(26):2574-6.
7. Fotuhi M, Mian A, Meysami S, Raji CA. Neurobiology of COVID-19. J Alzheimers Dis. 2020;76(1):3-19.

8. Garcia MA, Barreras PV, Lewis A, Pinilla G, Sokoll LJ, Kickler T, Mostafa H, Caturegli M, Moghekar A, Fitzgerald KC, NeuroCOVID H. Cerebrospinal fluid in COVID-19 neurological complications: no cytokine storm or neuroinflammation. medRxiv. Preprint. 2021. doi: https://doi.org/10.1101/2021.01.10.20249 014

9. Jarrahi A, Ahluwalia M, Khodadadi H, Salles ED, Kolhe R, Hess DC, Vale F, Kumar M, Baban B, Vaibhav K, Dhandapani KM. Neurological consequences of COVID-19: What have we learned and where do we go from here? J Neuroinflammation. 2020;17(1):286.

10. Felsenstein S, Herbert JA, McNamara PS, Hedrich CM. COVID-19: immunology and treatment options. Clin Immunol. 2020;215:108448.

11. Lucherini OM, Rigante D, Sota J, Fabiani C, Obici L, Cattalini $\mathrm{M}$, et al. Updated overview of molecular pathways involved in the most common monogenic autoinflammatory diseases. Clin Exp Rheumatol. 2018;36(1):3-9.

12. Schnappauf O, Chae JJ, Kastner DL, Aksentijevich I. The pyrin inflammasome in health and disease. Front Immunol. 2019;10:1745.

13. Catanzaro M, Fagiani F, Racchi M, Corsini E, Govoni S, Lanni C. Immune response in COVID-19: addressing a pharmacological challenge by targeting pathways triggered by SARS-CoV-2. Signal Transduct Target Ther. 2020;5(1):1-10.

14. Kumar S, Nyodu R, Maurya VK, Saxena SK. Host Immune Response and Immunobiology of Human SARS-CoV-2 Infection. In Coronavirus Disease 2019 (COVID-19) 2020;43-53.

15. Kopecky-Bromberg SA, Martínez-Sobrido L, Frieman M, Baric RA, Palese P. Severe acute respiratory syndrome coronavirus open reading frame (ORF) 3b, ORF 6, and nucleocapsid proteins function as interferon antagonists. J Virol. 2007;81(2):548-57. 
16. Meftahi GH, Jangravi Z, Sahraei H, Bahari Z. The possible pathophysiology mechanism of cytokine storm in elderly adults with COVID-19 infection: the contribution of "inflame-aging." Inflamm Res. 2020;69:825-39.

17. Meftahi GH, Bahari Z, Jangravi Z, Iman M. A vicious circle between oxidative stress and cytokine storm in ARDS pathogenesis during COVID-19 infection. Ukr Biochem J. 2021;93(1):19-29.

18. Xudong X, Junzhu C, Xingxiang W, Furong Z, Yanrong L. Ageand gender-related difference of ACE2 expression in rat lung. Life Sci. 2006;78(19):2166-71.

19. Chen J, Jiang Q, Xia X, Liu K, Yu Z, Tao W. Individual variation of the SARS-CoV2 receptor ACE2 gene expression and regulation. Aging Cell. 2020;19(7):e13168.

20. Ebadi M, Montano-Loza AJ. Perspective: improving vitamin D status in the management of COVID-19. Eur J Clin Nutr. 2020;74:856-9.

21. Cao X. COVID-19: immunopathology and its implications for therapy. Nature Rev Immunol. 2020;20(5):269-70.

22. Dinarello CA, Simon A, Van Der Meer JW. Treating inflammation by blocking interleukin-1 in a broad spectrum of diseases. Nature Rev Drug Dis. 2012;11(8):633-52.

23. Dinarello CA. Interleukin-1 in the pathogenesis and treatment of inflammatory diseases. Am J Hematol. 2011;117(14):3720-32.

24. Berda-Haddad Y, Robert S, Salers P, Zekraoui L, Farnarier C, Dinarello CA, et al. Sterile inflammation of endothelial cellderived apoptotic bodies is mediated by interleukin- $1 \alpha$. Proc Natl Acad Sci USA. 2011;108(51):20684-9.

25. Dinarello C A, Ikejima T, Warner SJ, Orencole SF, Lonnemann, $\mathrm{G}$, Cannon JG, et al. Interleukin 1 induces interleukin 1. I. Induction of circulating interleukin 1 in rabbits in vivo and in human mononuclear cells in vitro. J Immunol. 1987;139(6):1902-1910.

26. Weber A, Wasiliew P, Kracht M. Interleukin-1 (IL-1) pathway. Sci Signal. 2010;3(105):1.

27. Ahmadi H, Boroujeni ME, Sadeghi Y, Abdollahifar MA, Khodagholi F, Meftahi GH, et al. Sertoli cells avert neuroinflammation-induced cell death and improve motor function and striatal atrophy in rat model of Huntington disease. J Mol Neurosci. 2018;65(1):17-27.

28. Efati M, Khorrami M, Jangravi Z, Mahmoudabadi AZ, Raeiszadeh M, Sarshoori JR. HESA-A Attenuates Hepatic Steatosis in NAFLD Rat Model Through the Suppression of SREBP-1c and NF-k $\beta$. Int J Pept Res Ther. 2019;1-8.

29. Channappanavar R, Perlman S. Pathogenic human coronavirus infections: causes and consequences of cytokine storm and immunopathology. Semin Immunopathol. 2017;39(5):529-39.

30. Ruan Q, Yang K, Wang W, Jiang L, Song J. Clinical predictors of mortality due to COVID-19 based on an analysis of data of 150 patients from Wuhan. China Inten Care Med. 2020;46(5):846-8.

31. Şahin A, Derin ME, Albayrak F, Karakaş B, Karagöz Y. Assessment of effectiveness of anakinra and canakinumab in patients with colchicine-resistant/unresponsive familial Mediterranean fever. Adv Rheumatol. 2020;60(1):12.

32. Muskardin TL. Intravenous Anakinra for macrophage activation syndrome may hold lessons for treatment of cytokine storm in the setting of coronavirus disease 2019. ACR Open Rheumatol. 2020;2(5):283.

33. Monteagudo LA, Boothby A, Gertner E. Continuous intravenous anakinra infusion to calm the cytokine storm in macrophage activation syndrome. ACR Open Rheumatol. 2020;2(5):276-82.

34. Shakoory B, Carcillo JA, Chatham WW, Amdur RL, Zhao H, Dinarello CA, et al. Interleukin-1 receptor blockade is associated with reduced mortality in sepsis patients with features of the macrophage activation syndrome: re-analysis of a prior Phase III trial. Critical Care Med. 2016;44(2):275.
35. Ramírez J. Cañete JD (2018) Anakinra for the treatment of rheumatoid arthritis: a safety evaluation. Expert Opin Drug Saf. 2018;17(7):727-32.

36. Aouba A, Baldolli A, Geffray L, Verdon R, Bergot E, MartinSilva N, et al. Targeting the inflammatory cascade with anakinra in moderate to severe COVID-19 pneumonia: case series. Ann Rheum Dis. 2020;1-2.

37. Cavalli G, De Luca G, Campochiaro C, Della-Torre E, Ripa M, Canetti D, et al. Interleukin-1 blockade with high-dose anakinra in patients with COVID-19, acute respiratory distress syndrome, and hyperinflammation: a retrospective cohort study. Lancet Rheumatol. 2020;2(6):325-31.

38. Yang BB, Gozzi P, Sullivan JT. Pharmacokinetics of anakinra in subjects of heavier vs. lighter body weights. Clin Trans Sci. 2019;12(4):371-8.

39. King A, Vail A, O'Leary C, Hannan C, Brough D, Patel H, et al. Anakinra in COVID-19: important considerations for clinical trials. Lancet Rheumatol. 2020;2(7):379-81.

40. Filocamo G, Mangioni D, Tagliabue P, Aliberti S, Costantino G, Minoia F, et al. Use of anakinra in severe COVID-19: a case report. Internation J Infect Dis. 2020;96:607-9.

41. Zhou F, Yu T, Du R, Fan G, Liu Y, Liu Z, et al. Clinical course and risk factors for mortality of adult inpatients with COVID19 in Wuhan, China: a retrospective cohort study. Lancet. 2020;395(10229):1054-62.

42. Ucciferri C, Auricchio A, Di Nicola M, Potere N, Abbate A, Cipollone F, et al. Canakinumab in a subgroup of patients with COVID-19. Lancet Rheumatol. 2020;2(8):457-8

43. Wang L, Zhang Y, Zhang S. Cardiovascular impairment in COVID-19: learning from current options for cardiovascular anti-inflammatory therapy. Front Cardiovasc Med. 2020;7:78.

44. Hoffman HM, Throne ML, Amar NJ, Sebai M, Kivitz AJ, Kavanaugh A, et al. Efficacy and safety of rilonacept (interleukin-1 Trap) in patients with cryopyrin-associated periodic syndromes: results from two sequential placebo-controlled studies. Arthritis Rheum. 2008;58(8):2443-52.

45. Varan Ö, Kucuk H, Babaoglu H, Guven SC, Ozturk MA, Haznedaroglu S, et al. Efficacy and safety of interleukin-1 inhibitors in familial Mediterranean fever patients complicated with amyloidosis. Mod Rheumatol. 2019;29(2):363-6.

46. Kapur S, Bonk ME. Rilonacept (arcalyst), an interleukin-1 trap for the treatment of cryopyrin-associated periodic syndromes. Pharm Therap. 2009;34(3):138.

47. Karkhur S, Hasanreisoglu M, Vigil E, Halim MS, Hassan M, Plaza C, et al. Interleukin-6 inhibition in the management of non-infectious uveitis and beyond. J Ophthalmic Inflamm Infect. 2019;9(1):17.

48. Han H, Ma Q, Li C, Liu R, Zhao L, Wang W, et al. Profiling serum cytokines in COVID-19 patients reveals IL-6 and IL-10 are disease severity predictors. Emerg Microbes Infect. 2020;9(1):1123-30.

49. Wan S, Yi Q, Fan S, Lv J, Zhang X, Guo L, et al. Characteristics of lymphocyte subsets and cytokines in peripheral blood of 123 hospitalized patients with 2019 novel coronavirus pneumonia (NCP). MedRxiv. 2020.

50. Magro G. SARS-CoV-2 and COVID-19: is interleukin-6 (IL6 ) the'culprit lesion' of ARDS onset? What is there besides Tocilizumab? SGP130Fc. Cytokine. 2020;2(2):100029.

51. Zhang C, Wu Z, Li JW, Zhao H, Wang GQ. The cytokine release syndrome (CRS) of severe COVID-19 and Interleukin-6 receptor (IL-6R) antagonist Tocilizumab may be the key to reduce the mortality. Int J Antimicrob Agents. 2020;55(5):105954.

52. Lauder SN, Jones E, Smart K, Bloom A, Williams AS, Hindley $\mathrm{JP}$, et al. Interleukin-6 limits influenza-induced inflammation 
and protects against fatal lung pathology. Europ J Immunol. 2013;43(10):2613-25.

53. Okabayashi T, Kariwa H, Yokota SI, Iki S, Indoh T, Yokosawa $\mathrm{N}$, et al. Cytokine regulation in SARS coronavirus infection compared to other respiratory virus infections. J Med Virol. 2006;78(4):417-24.

54. Gong J, Dong H, Xia SQ, Huang YZ, Wang D, Zhao Y, et al. Correlation analysis between disease severity and inflammation-related parameters in patients with COVID-19 pneumonia. MedRxiv. 2020.

55. Wolf J, Rose-John S, Garbers C. Interleukin-6 and its receptors: a highly regulated and dynamic system. Cytokine. 2014;70(1):11-20.

56. Schaper F, Rose-John S. Interleukin-6: biology, signaling and strategies of blockade. Cytokine Growth F R. 2015;26(5):475-87.

57. Müllberg J, Vollmer P, Althoff K, März P, Rose-John S. Generation and function of the soluble interleukin- 6 receptor. Biochem Soc Trans. 1999;27(2):211-9.

58. Riethmueller S, Ehlers JC, Lokau J, Düsterhöft S, Knittler K, Dombrowsky G, et al. Cleavage site localization differentially controls interleukin- 6 receptor proteolysis by ADAM10 and ADAM17. Sci Rep. 2016;6:25550.

59. Riethmueller S, Somasundaram P, Ehlers JC, Hung CW, Flynn $\mathrm{CM}$, Lokau J, et al. Proteolytic origin of the soluble human IL-6R in vivo and a decisive role of N-glycosylation. PLoS Biol. 2017;15(1):e2000080.

60. Rose-John S. The soluble interleukin 6 receptor: advanced therapeutic options in inflammation. Clin Pharmacol Therap. 2017; 102(4):591-8.

61. Rose-John S, Heinrich PC. Soluble receptors for cytokines and growth factors: generation and biological function. Biochem J. 1994;300(2):281-90.

62. Rose-John S, Schooltink H, Lenz D, Hipp E, Dufhues G, Schmitz H, et al. Studies on the structure and regulation of the human hepatic interleukin-6 receptor. Europ J Biochem. 1990;190(1):79-83.

63. Oberg HH, Wesch D, Grüssel S, Rose-John S, Kabelitz D. Differential expression of CD126 and CD130 mediates different STAT-3 phosphorylation in CD4+ CD25- and CD25high regulatory T cells. Int Immunol. 2006;18(4):555-63.

64. Scheller J, Garbers C, Rose-John S. Interleukin-6: from basic biology to selective blockade of pro-inflammatory activities. Sem Immunol. 2014;26(1):2-12.

65. Barkhausen T, Tschernig T, Rosenstiel P, van Griensven M, Vonberg RP, Dorsch M, et al. Selective blockade of interleukin-6 trans-signaling improves survival in a murine polymicrobial sepsis model. Crit Care Med. 2011;39(6):1407-13.

66. Sarosiek S, Shah R, Munshi NC. Review of siltuximab in the treatment of multicentric Castleman's disease. Ther Adv Hematol. 2016;7(6):360-6.

67. Tanaka T, Narazaki M, Kishimoto T. Therapeutic targeting of the interleukin-6 receptor. Annu Rev Pharmacol Toxicol. 2012;52:199-219.

68. Xu X, Han M, Li T, Sun W, Wang D, Fu B, et al. Effective treatment of severe COVID-19 patients with tocilizumab. Proc Natl Acad Sci USA. 2020;117(20):10970-5.

69. Luo P, Liu Y, Qiu L, Liu X, Liu D, Li J. Tocilizumab treatment in COVID-19: A single center experience. J Med Virol. 2020;92(7):814-8.

70. Mihai C, Dobrota R, Schröder M, Garaiman A, Jordan S, Becker MO, et al. COVID-19 in a patient with systemic sclerosis treated with tocilizumab for SSc-ILD. Ann Rheum Dis. 2020;79(5):668-9.
71. Fontana F, Alfano G, Mori G, Amurri A, Tei L, Ballestri M, et al. Covid-19 pneumonia in a kidney transplant recipient successfully treated with Tocilizumab and Hydroxychloroquine. Am J Transp. 2020;20(7):1902-6.

72. Zhang S, Li L, Shen A, Chen Y, Qi Z. Rational use of tocilizumab in the treatment of novel coronavirus pneumonia. Clini Drug Invest. 2020;40(6):511-8.

73. Ferfar Y, Mirault T, Desbois AC, Comarmond C, Messas E, Savey $\mathrm{L}$, et al. Biotherapies in large vessel vasculitis. Autoimm Rev. 2016;15(6):544-51.

74. Samson M, Devilliers H, Ly KH, Maurier F, Bienvenu B, Terrier $\mathrm{B}$, et al. Tocilizumab as an add-on therapy to glucocorticoids during the first 3 months of treatment of Giant cell arteritis: a prospective study. Europ J Int Med. 2018;57:96-104.

75. Jones G, Ding C. Tocilizumab: a review of its safety and efficacy in rheumatoid arthritis. Clin Med Insights Arthritis Musculoskelet Disord. 2010;3:81-9.

76. Hoge J, Yan I, Jänner N, Schumacher V, Chalaris A, Steinmetz OM, et al. IL-6 controls the innate immune response against Listeria monocytogenes via classical IL-6 signaling. J Immunol. 2013;190(2):703-11.

77. Wunderlich CM, Delić D, Behnke K, Meryk A, Ströhle P, Chaurasia B, et al. Cutting edge: Inhibition of IL-6 trans-signaling protects from malaria-induced lethality in mice. J Immunol. 2012;188(9):4141-4.

78. Scheller J, Chalaris A, Schmidt-Arras D, Rose-John S. The proand anti-inflammatory properties of the cytokine interleukin-6. Biochim Biophys Acta. 2011;1813(5):878-88.

79. Deisseroth A, Ko CW, Nie L, Zirkelbach JF, Zhao L, Bullock J, et al. FDA approval: siltuximab for the treatment of patients with multicentric Castleman disease. Clin Cancer Res. 2015;21(5):950-4.

80. European Medicines Agency. Summary of product characteristics of siltuximab. Agencia Española de Medicamentos Y Productos Sanitarios, Available: https://cima.aemps.es/cima/pdfs/ft/11492 8001/FT_114928001.pdf. 2019

81. Gritti G, Raimondi F, Ripamonti D, Riva I, Landi F, Alborghetti $\mathrm{L}$, et al. Use of siltuximab in patients with COVID-19 pneumonia requiring ventilatory support. MedRxiv. 2020.

82. van Rhee F, Casper C, Voorhees PM, Fayad LE, Gibson D, Kanhai K, et al. Long-term safety of siltuximab in patients with idiopathic multicentric Castleman disease: a prespecified, open-label, extension analysis of two trials. Lancet Haematol. 2020;7(3):209-17.

83. Kim S, Östör AJ, Nisar MK. Interleukin-6 and cytochrome-P450, reason for concern? Rheumatol int. 2012;32(9):2601-4.

84. Casper C, Chaturvedi S, Munshi N, Wong R, Qi M, Schaffer M, et al. Analysis of inflammatory and anemia-related biomarkers in a randomized, double-blind, placebo-controlled study of siltuximab (anti-IL6 monoclonal antibody) in patients with multicentric Castleman disease. Clin Cancer Res. 2015;21(19):4294-304.

85. Bloomfield M, Parackova Z, Cabelova T, Pospisilova I, Kabicek $\mathrm{P}$, Houstkova H, et al. Anti-IL6 autoantibodies in an infant with CRP-less septic shock. Front Immunol. 2019;10:2629.

86. Benucci M, Giannasi G, Cecchini P, Gobbi FL, Damiani A, Grossi V, et al. COVID-19 pneumonia treated with Sarilumab: a clinical series of eight patients. J Med Virol. 2020;1-3.

87. Li SF, Gong MJ, Zhao FR, Shao JJ, Xie YL, Zhang YG, et al. Type I interferons: distinct biological activities and current applications for viral infection. Cell Physiol Biochem. 2018;51(5):2377-96.

88. Lin FC, Young HA. Interferons: success in anti-viral immunotherapy. Cytokine Growth F R. 2014;25(4):369-76.

89. Zhou H, Chen S, Wang M, Cheng A. Interferons and their receptors in birds: a comparison of gene structure, 
phylogenetic analysis, and cross modulation. Int J Mol Sci. 2014;15(11):21045-68.

90. Platanias LC. Mechanisms of type-I-and type-II-interferonmediated signalling. Nat Rev Immunol. 2005;5(5):375-86.

91. Sun L, Wu J, Du F, Chen X, Chen ZJ. Cyclic GMP-AMP synthase is a cytosolic DNA sensor that activates the type I interferon pathway. Science. 2013;339(6121):786-91.

92. Lee AJ, Ashkar AA. The dual nature of type I and type II interferons. Front Immunol. 2018;9:2061.

93. Gill N, Chenoweth MJ, Verdu EF, Ashkar AA. NK cells require type I IFN receptor for antiviral responses during genital HSV-2 infection. Cell Immunol. 2011;269(1):29-37.

94. Gotthardt D, Sexl V. STATs in NK-cells: the good, the bad, and the ugly. Front Immunol. 2017;7:694.

95. NanY, Wu C, Zhang YJ. Interferon independent non-canonical STAT Activation and virus induced inflammation. Viruses. 2018;10(4):196.

96. Sutter K, Dickow J, Dittmer U. Interferon $\alpha$ subtypes in HIV infection. Cytokine Growth F R. 2018;40:13-8.

97. Madsen C. The innovative development in interferon beta treatments of relapsing-remitting multiple sclerosis. Brain Behav. 2017;7(6):e00696.

98. Loutfy MR, Blatt LM, Siminovitch KA, Ward S, Wolff B, Lho $\mathrm{H}$, et al. Interferon alfacon-1 plus corticosteroids in severe acute respiratory syndrome: a preliminary study. JAMA. 2003;290(24):3222-8.

99. Scagnolari C, Trombetti S, Alberelli A, Cicetti S, Bellarosa D, Longo R, et al. The synergistic interaction of interferon types I and II leads to marked reduction in severe acute respiratory syndrome-associated coronavirus replication and increase in the expression of mRNAs for interferon-induced; proteins. Intervirol. 2007;50(2):156-60.

100. Sallard E, Lescure FX, Yazdanpanah Y, Mentre F, Peiffer-Smadja $\mathrm{N}$, Florence AD. Type 1 interferons as a potential treatment against COVID-19. Antiviral Res. 2020;104791.

101. Arabi YM, Shalhoub S, Al Omari A, Mandourah Y, Al-Hameed $\mathrm{F}$, Sindi A, et al. Effect of ribavirin and interferon on the outcome of critically ill patients with MERS. In C63. VIiral Resp Infect. 2017;6067-6067.

102. Sheahan TP, Sims AC, Leist SR, Schäfer A, Won J, Brown AJ, et al. Comparative therapeutic efficacy of remdesivir and combination lopinavir, ritonavir, and interferon beta against MERSCoV. Nature Comm. 2020;11(1):1-4.

103. Zhao Z, Zhang F, Xu M, Huang K, Zhong W, Cai W, et al. Description and clinical treatment of an early outbreak of severe acute respiratory syndrome (SARS) in Guangzhou. PR China $\mathbf{J}$ Med Microbial. 2003;52(8):715-20.

104. Omrani AS, Saad MM, Baig K, Bahloul A, Abdul-Matin M, Alaidaroos AY, et al. Ribavirin and interferon alfa-2a for severe Middle East respiratory syndrome coronavirus infection: a retrospective cohort study. Lancet Infect Dis. 2014;14(11):1090-5.

105. Schreiber $\mathrm{G}$. The molecular basis for differential type I interferon signaling. J Biol Chem. 2017;292(18):7285-94.

106. James CM, Abdad MY, Mansfield JP, Jacobsen HK, Vind AR, Stumbles PA, et al. Differential activities of alpha/beta IFN subtypes against influenza virus in vivo and enhancement of specific immune responses in DNA vaccinated mice expressing haemagglutinin and nucleoprotein. Vaccine. 2007;25(10):1856-67.

107. Scagnolari C, Vicenzi E, Bellomi F, Stillitano MG, Pinna D, Poli $\mathrm{G}$, et al. Increased sensitivity of SARS-coronavirus to a combination of human type I and type II interferons. Antivir Ther. 2004;9(6):1003-11.

108. Chan JF, Chan KH, Kao RY, To KK, Zheng BJ, Li CP, et al. Broad-spectrum antivirals for the emerging Middle East respiratory syndrome coronavirus. J Infect. 2013;67(6):606-16.
109. Dong L, Hu S, Gao J. Discovering drugs to treat coronavirus disease 2019 (COVID-19). Drug Discov Therap. 2020;14(1):58-60.

110. Bellingan G, Maksimow M, Howell DC, Stotz M, Beale R, Beatty M, et al. The effect of intravenous interferon-beta-1a (FP-1201) on lung CD73 expression and on acute respiratory distress syndrome mortality: an open-label study. Lancet Resp Med. 2014;2(2):98-107.

111. Lokugamage KG, Hage A, Schindewolf C, Rajsbaum R, Menachery VD. SARS-CoV-2 is sensitive to type I interferon pretreatment. BioRxi.2020.

112. Payandemehr P, Azhdarzadeh M, Bahrami-Motlagh H, Hadadi A, Najmeddin F, Shahmirzaei S, et al. Interferon beta-1a as a candidate for COVID-19 treatment; an open-label single-arm clinical trial. Adv J Emerg Med. 2020;4(2):51-51.

113. Channappanavar R, Fehr AR, Zheng J, Wohlford-Lenane C, Abrahante JE, Mack M, et al. IFN-I response timing relative to virus replication determines MERS coronavirus infection outcomes. J Clin Invest. 2019;129(9).

114. Seif F, Aazami H, Khoshmirsafa M, Kamali M, Mohsenzadegan M, Pornour M, et al. JAK inhibition as a new treatment strategy for patients with COVID-19. Int Arch Allergy Immunol. 2020;181(6):467-75.

115. Luo W, Li YX, Jiang LJ, Chen Q, Wang T, Ye DW. Targeting JAK-STAT signaling to control cytokine release syndrome in COVID-19. Trends Pharmacolog Sci. 2020;41(8):531-43.

116. Kawalec P, Śladowska K, Malinowska-Lipień I, Brzostek T, Kózka M. New alternative in the treatment of rheumatoid arthritis: clinical utility of baricitinib. Ther Clin Risk Manag. 2019;15:275.

117. Cameron MJ, Bermejo-Martin JF, Danesh A, Muller MP, Kelvin DJ. Human immunopathogenesis of severe acute respiratory syndrome (SARS). Virus Res. 2008;133(1):13-9.

118. Russell B, Moss C, George G, Santaolalla A, Cope A, Papa S, et al. Associations between immune-suppressive and stimulating drugs and novel COVID-19-a systematic review of current evidence. Ecancermedicalscience. 2020;14:1022.

119. European Medicines Agency. Olumiant (baricitinib). 2019; https ://www.ema.europa.eu/en/medicines/human/EPAR/olumiant

120. Richardson P, Griffin I, Tucker C, Smith D, Oechsle O, Phelan A, et al. Baricitinib as potential treatment for 2019-nCoV acute respiratory disease. Lancet. 2020;395(10223):e30.

121. Schett G, Manger B, Simon D, Caporali R. COVID-19 revisiting inflammatory pathways of arthritis. Nature Rev Rheumatol. 2020;16:465-70.

122. Stebbing J, Phelan A, Griffin I, Tucker C, Oechsle O, Smith D, et al. COVID-19: combining antiviral and anti-inflammatory treatments. Lancet Infect Dis. 2020;20(4):400-2.

123. Sanchez GA, Reinhardt A, Ramsey S, Wittkowski H, Hashkes PJ, Berkun Y, et al. JAK1/2 inhibition with baricitinib in the treatment of autoinflammatory interferonopathies. J Clin Invest. 2018;128(7):3041-52.

124. Madej M, Woytala P, Frankowski M, Lubiński Ł, Sokolik R, Sebastian A, et al. Tofacitinib in the treatment of active rheumatoid arthritis-single-centre experience. Reumatologia. 2019;57(4):192.

125. Charles-Schoeman C, Gonzalez-Gay MA, Kaplan I, Boy M, Geier J, Luo Z, et al. Effects of tofacitinib and other DMARDs on lipid profiles in rheumatoid arthritis: implications for the rheumatologist. Semin Arthritis Rheum. 2016;46(1):71-80.

126. Ma Y, Wang C, Xue M, Fu F, Zhang X, Li L, et al. Coronavirus TGEV evades the type I interferon response through IRE1 $\alpha$ mediated manipulation of the miR-30a-5p/SOCS1/3 Axis. J Virol. 2018. https://doi.org/10.1128/JVI.00728-18.

127. Furqan M, Mukhi N, Lee B, Liu D. Dysregulation of JAK-STAT pathway in hematological malignancies and JAK inhibitors for clinical application. Biomarker Res. 2013;1(1):5. 
128. Cao Y, Wei J, Zou L, Jiang T, Wang G, Chen L, et al. Ruxolitinib in treatment of severe coronavirus disease 2019 (COVID-19): A multicenter, single-blind, randomized controlled trial. J Allergy Clin Immunol. 2020;146(1):137-146.e3.

129. Jawhara S. Could intravenous immunoglobulin collected from recovered coronavirus patients protect against COVID-19 and strengthen the immune system of new patients? Int J Mol Sci. 2020;21:2272.

130. Subbarao K, Mordant F, Rudraraju R. Convalescent plasma treatment for COVID-19: Tempering expectations with the influenza experience. Eur J Immunol. 2020;50:1447-53.

131. Mair-Jenkins J, Saavedra-Campos M, Baillie JK, Cleary P, Khaw FM, Lim WS, Makki S, et al. The effectiveness of convalescent plasma and hyperimmune immunoglobulin for the treatment of severe acute respiratory infections of viral etiology: a systematic review and exploratory meta-analysis. J Infect Dis. 2015;211:80-90.

132. Ahn JY, Sohn Y, Lee SH, Cho Y, Hyun JH, Baek YJ, Jeong SJ, Kim JH, Ku NS, Yeom JS, Roh J. Use of convalescent plasma therapy in two COVID-19 patients with acute respiratory distress syndrome in Korea. J Korean Med Sci. 2020;35:e149.

133. Shen C, Wang Z, Zhao F, Yang Y, Li J, Yuan J, Wang F, Li D, Yang M, Xing L, Wei J. Treatment of 5 critically ill patients with COVID-19 with convalescent plasma. JAMA. 2020;323(16):1582-9.

134. Liu ST, Lin HM, Baine I, Wajnberg A, Gumprecht JP, Rahman F, Rodriguez D, Tandon P, Bassily-Marcus A, Bander J, Sanky C. Convalescent plasma treatment of severe COVID19: a propensity score-matched control study. Nat Med. 2020;26(11):1708-13.

Publisher's Note Springer Nature remains neutral with regard to jurisdictional claims in published maps and institutional affiliations. 